Check for updates

Cite this: RSC Adv., 2017, 7, 42725

Received 20th June 2017

Accepted 30th August 2017

DOI: 10.1039/c7ra06895f

rsc.li/rsc-advances

\section{Simultaneous enhancement of natural sunlight- and artificial UV-driven photocatalytic activity of a mechanically activated $\mathrm{ZnO} / \mathrm{SnO}_{2}$ composite}

\author{
Smilja Marković, (D) *a Ana Stanković, ${ }^{a}$ Jasmina Dostanić, ${ }^{\mathrm{b}}$ Ljiljana Veselinović, ${ }^{a}$ \\ Lidija Mančić, ${ }^{a}$ Srečo Davor Škapin, ${ }^{c}$ Goran Dražič, ${ }^{d}$ Ivona Janković-Častvan ${ }^{e}$ \\ and Dragan Uskokovića
}

Mechanical milling of commercial $\mathrm{ZnO}$ and $\mathrm{SnO}_{2}$ was used to produce a $\mathrm{ZnO} / \mathrm{SnO}_{2}$ composite with a high density of surface defects; in particular, zinc interstitials $\left(Z n_{i}\right)$ and oxygen vacancies $\left(V_{O}\right)$. To determine the impact of surface defects on photocatalytic activity, the relative concentration ratio of bulk defects to surface defects was modified by annealing at 400 and $700{ }^{\circ} \mathrm{C}$. The possible application of the $\mathrm{ZnO} / \mathrm{SnO}_{2}$ composite as a natural sunlight and UV-light driven photocatalyst was revealed via de-colorization of methylene blue. In both cases the $\mathrm{ZnO} / \mathrm{SnO}_{2}$ composite exhibited enhanced photocatalytic activity as compared to the pristine $\mathrm{ZnO}$. In order to investigate the origin of the enhancement, the pristine metal oxides and composites were characterized using a variety of techniques, including X-ray diffraction (XRD), Raman and Fourier transform infrared (FTIR) spectroscopy, field emission scanning electron microscopy (FESEM), laser diffraction particle size analysis, Brunauer-Emmett-Teller, UV-Vis diffuse reflectance and photoluminescence spectroscopy. High-resolution transmission electron microscopy (HRTEM) and elemental mapping analyses were used to reveal the presence of $\mathrm{SnO}_{2}$ nanocrystallites on the surface of larger $\mathrm{ZnO}$ particles. The enhanced photocatalytic activity of the composite can be attributed to the synergetic effect of the surface defects and the $\mathrm{ZnO} / \mathrm{SnO}_{2}$ heterojunction particles, which facilitated charge separation, thereby hindering the recombination of photogenerated carriers. This study draws attention to mechanical activation as an inexpensive and environmentally friendly technique for the large-scale production of the composite with an enhanced photocatalytic activity under illumination of either UV or sunlight.

\section{Introduction}

Over the past four decades, since Fujishima and Honda reported the photoelectrolysis of water using a $\mathrm{TiO}_{2}$ as photoanode, ${ }^{\mathbf{1}}$ numerous efforts have been made by environmental and materials scientists to develop highly efficient semiconductor photocatalysts for degradation of organic and biological pollutants in water under light irradiation., ${ }^{2,3}$ The main advantage of photocatalytical disinfection, purification or remediation of drinking and wastewater is a complete mineralization of pollutants to inorganic salts, water and carbon dioxide, without any trace of secondary pollution. ${ }^{4}$ Metal oxides such as $\mathrm{ZnO}, \mathrm{TiO}_{2}, \mathrm{SnO}_{2}, \mathrm{Fe}_{2} \mathrm{O}_{3}, \mathrm{~V}_{2} \mathrm{O}_{5}$, and so on, are recognized

\footnotetext{
${ }^{a}$ Institute of Technical Sciences of SASA, Knez Mihailova 35/IV, 11000 Belgrade, Serbia. E-mail: smilja.markovic@itn.sanu.ac.rs; Fax: +381 112185263

${ }^{b}$ University of Belgrade, IChTM Center for Catalysis, Belgrade, Serbia

'Jožef Stefan Institute, Jamova 39, 1000 Ljubljana, Slovenia

${ }^{d}$ Laboratory for Materials Chemistry, National Institute of Chemistry, Ljubljana, Slovenia

${ }^{e}$ Faculty of Technology and Metallurgy, University of Belgrade, Belgrade, Serbia
}

as useful materials to initiate photoreaction due to their high photoactivity and photostability, good chemical and biological inertness, inexpensiveness and easy production. ${ }^{3,5}$ Due to the wide band gap energy, in the range of 3.3-3.6 eV, these metal oxides can be activated by UV light only, while they are nonefficient under visible range of sunlight or indoor light irradiation. ${ }^{6,7}$ According to the World Meteorological Organization, the outer atmosphere of the Earth receives approximately $1367 \mathrm{~W} \mathrm{~m}^{-2}$ of insolation, ${ }^{8}$ promoting sunlight as a renewable, free and clean energy source. Solar irradiation which comes to the Earth is spread over ultraviolet, visible and infrared frequency range, where UV-light makes no more than 3-5\%, while visible light makes about $45 \%$ of the total amount. Thus, to use solar energy for initiating of photocatalytic or photoelectrolytic reaction it is necessary to modify the metal oxides to be photo-active under visible light irradiation or to increase activity under UV light. ${ }^{9}$ To modify the optical absorption and to improve the sunlight photonic activity of the metal oxides different approaches have been developed, such as: the incorporation of transition metal ions into the crystal structure, sensitization of the particles' surface, hydrogenation, the 
incorporation of crystalline defects in metal oxide semiconductors in the form of vacancies and interstitials, etc. ${ }^{\mathbf{1 0 - 1 4}}$ Mechanical activation is recognized as an attractive approach to introduce point defects on a surface or into the crystal structure of metal oxides, ${ }^{15}$ consequently improving the visible light absorption. However, a wide practical application of photocatalysts, even with enhanced visible light absorption, is hindered by the fast recombination of the photogenerated electron-hole pairs. ${ }^{16,17}$ It has been revealed that the recombination of photogenerated electron-hole can be efficiently reduced by application of a heterojunction structure ${ }^{18}$ where the heterojunction structure represents combination of at least two semiconductors with different band gap energies, enabling a better charge separation. Heterojunction composites such as $\mathrm{ZnO} / \mathrm{SnO}_{2}, \mathrm{TiO}_{2} / \mathrm{SnO}_{2}, \mathrm{ZnO} / \mathrm{TiO}_{2} / \mathrm{SnO}_{2}, \mathrm{SnO}_{2} / \mathrm{Fe}_{2} \mathrm{O}_{3}$, etc., have been developed, showing improved photocatalytic efficiency. ${ }^{17}$

A number of studies have confirmed that $\mathrm{ZnO} / \mathrm{SnO}_{2}$ nanostructured composites exhibit improved photocatalytic activity, high conversion efficiency of solar cell, gas sensing and electric properties, due to the formation of nano-heterojunctions. ${ }^{19-21}$ Many $\mathrm{ZnO} / \mathrm{SnO}_{2}$ heterojunctions can be easily formed in composites during a synthesis procedure due to similar crystal growth habit of $\mathrm{ZnO}$ and $\mathrm{SnO}_{2} \cdot{ }^{19}$ Besides better charge separation and reduced number of exciton recombination, the substitution of $\mathrm{Zn}^{2+}$ ions for $\mathrm{Sn}^{4+}$ would results in surface modification and formation of more oxygen vacancies in order to compensate the positive charge.

$\mathrm{ZnO} / \mathrm{SnO}_{2}$ photocatalysts have been synthesized by various techniques: hydrothermally, ${ }^{17,19,22}$ solvothermally, ${ }^{23}$ by coprecipitation, ${ }^{20}$ by sol-gel procedure, ${ }^{2}$ mechanochemically, ${ }^{24}$ etc. Moreover, core-shell $\mathrm{ZnO} / \mathrm{SnO}_{2}$ nanoneedle particles were prepared by two-step procedure, including hydrothermal processing and a coating. ${ }^{21}$ It have been shown that the photocatalytic properties of $\mathrm{ZnO} / \mathrm{SnO}_{2}$ composites are highly related to the particle size and shape, crystal structure, proportions between the metal oxides and so on.

Most of methods for synthesis of $\mathrm{ZnO} / \mathrm{SnO}_{2}$ composites include chemical reactions, often requiring very stringent control in various processing parameters, followed by annealing at elevated temperatures, together with a low production yield. The goal of our research was large-scale preparation of photocatalysts highly reactive under illumination of both UV and sunlight. We choose to modify commercial zinc oxide powder due to its band gap at the edge of ultraviolet part of the spectrum and high potential to be red-shifted, enabling use of a broader spectrum of sunlight. A mechanical milling was employed for processing of the photocatalyst particles since it enables introduction of surface defects which could promote red-shift of the band gap, what's more, surface defects could reduce the recombination of photogenerated electrons and holes. Small amount of commercial $\mathrm{SnO}_{2}$ powder (17 wt\%) was added to the $\mathrm{ZnO}$ powder to form $\mathrm{ZnO} / \mathrm{SnO}_{2}$ composite with heterojunction particles, thereby to more delay the recombination of photogenerated carriers through efficient charge separation based on different band gap energies. Here we report results of a systematical study of structural, morphological, textural and optical properties of the commercial $\mathrm{ZnO}$ and $\mathrm{SnO}_{2}$ powders as the ingredients, and composite made of them via simple mechanical milling. The photocatalytic activity of the samples was revealed through de-colorization of methylene blue under illumination of: (1) natural sunlight, and (2) UV lamp. The origin of the photocatalytic activity was discussed.

\section{Experimental}

\subsection{Synthesis of $\mathrm{ZnO} / \mathrm{SnO}_{2}$ photocatalysts}

$\mathrm{ZnO} / \mathrm{SnO}_{2}$ composite was prepared by high-energy ball milling of commercial metal oxide powders. Analytically grade $\mathrm{ZnO}$ (99\%, Sigma-Aldrich) and $\mathrm{SnO}_{2}$ (>99\%, Kemika, Zagreb) powders in a 0.9 : 0.1 molar ratio (83 wt\%: $17 \mathrm{wt} \%$ ) were mechanically treated during $2 \mathrm{~h}$ in planetary ball mill (Across International PQ-NO4) with stainless steel vessels (100 ml) and balls $(\varnothing 5 \mathrm{~mm})$. The balls to powder weight ratio was $10: 1$. The angular velocity of the vessels was $400 \mathrm{rpm}$. To prevent reagglomeration of broken oxide particles during processing, highenergy milling was done in an inert $\mathrm{NaCl}$ matrix resulting in the formation of a composite powder consisting of oxide grains embedded within a salt matrix. To remove the $\mathrm{NaCl}$ matrix, the obtained powder was rinsed five times with distilled water and subsequently two times with absolute ethanol; each time suspension was centrifuged at $5000 \mathrm{rpm}$ for $5 \mathrm{~min}$. The rinsed powder was air dried in an oven at $60^{\circ} \mathrm{C}$ for $24 \mathrm{~h}$.

In order to vary the relative concentration ratio of bulk defects to surface defects, $\mathrm{ZnO} / \mathrm{SnO}_{2}$ composite was annealed at 400 and $700{ }^{\circ} \mathrm{C}$. Annealing was done in a tube furnace in an air atmosphere, with a heating rate of $10^{\circ} \mathrm{min}^{-1}$ and a dwell time of $2 \mathrm{~h}$. The annealing temperatures were chosen from a thermogravimetric and differential thermal analysis (TG-DTA) of $\mathrm{ZnO} / \mathrm{SnO}_{2}$ composite. The analysis was determined by simultaneous TG-DTA (Setsys, SETARAM Instrumentation, Caluire, France) in the temperature range between 25 and $1000^{\circ} \mathrm{C}$ under the air flow of $20 \mathrm{ml} \mathrm{min}{ }^{-1}$, in an $\mathrm{Al}_{2} \mathrm{O}_{3}$ pan. The heating profile was set as follows: the material was stabilized at $25^{\circ} \mathrm{C}$ for $5 \mathrm{~min}$ then heated to $1000{ }^{\circ} \mathrm{C}$ with the heating rate of $10^{\circ} \mathrm{min}^{-1}$.

Throughout this paper, the synthesized photocatalysts are designated as ma- $\mathrm{ZnO} / \mathrm{SnO}_{2}, \mathrm{ZnO} / \mathrm{SnO}_{2}-400$ and $\mathrm{ZnO} / \mathrm{SnO}_{2}-700$, where "ma" denotes a process of the mechanical activation, while the numbers denote the annealing temperatures, 400 and $700{ }^{\circ} \mathrm{C}$, respectively.

\subsection{Characterization}

$\mathrm{X}$-ray diffraction (XRD) data were recorded on a Philips PW-1050 operated at $40 \mathrm{kV}$ and $20 \mathrm{~mA}$ with $\mathrm{Cu} \mathrm{K} \alpha_{1,2}$ radiation. The data were collected over a $2 \theta$ range $10-70^{\circ}$ with a step of $0.05^{\circ}$ and a counting time of $5 \mathrm{~s}$ per step. The crystal phases were identified by comparing the recorded data with those reported in the Joint Committee of Powder Diffraction Standards (JCPDS) database. The unit cell parameters were calculated through La Bail refinement using Topas academic software. ${ }^{25}$ The crystallite sizes $(D)$ were calculated from the XRD line-broadening using the Scherrer equation $D=K \lambda / \beta_{\mathrm{m}} \cos \theta$, where $K$ is the shape coefficient and is equal to $0.89 ; \lambda$ is the wavelength of $\mathrm{X}$-ray radiation $(1.54178 \AA) ; \beta_{\mathrm{m}}$ is the full width at half maximum 
(FWHM) for the XRD reflection, while $\theta$ is the diffraction angle $\left({ }^{\circ}\right) .^{26,27}$ Fourier transform infrared (FT-IR) spectra were recorded on a Thermo Scientific ${ }^{\mathrm{TM}}$ Nicolet $^{\mathrm{TM}}$ iS $^{\mathrm{TM}} 10$ FT-IR Spectrometer equipped with attenuated total reflectance (ATR) accessory. The ATR/FT-IR measurements were done in the wavenumber region of $400-2000 \mathrm{~cm}^{-1}$, with a resolution of $4 \mathrm{~cm}^{-1}$. The roomtemperature Raman spectra were taken in the backscattering geometry using a $\mu$-Raman system with a Jobin Yvon T64000 triple monochromator, equipped with a liquid nitrogen-cooled CCD detector. The excitation was done by the $514.5 \mathrm{~nm}$ line of an Ar-ion laser. The spectra were recorded in the wavenumber interval of $80-1200 \mathrm{~cm}^{-1}$ with a resolution of $4 \mathrm{~cm}^{-1}$. The morphology of composite particles was observed by field emission scanning electron microscopy (FESEM, Ultra plus, Carl Zeiss, Germany). The samples for the FESEM analysis were dispersed in ethanol, in ultrasonic bath, for $5 \mathrm{~min}$; after dispersion a few drops were filtered through a polycarbonate membrane. The membrane was put on the carbon tape on the aluminum stub and carbon-coated in order to prevent electron charging. Before analysis the sample was vacuumed for $15 \mathrm{~min}$. Particle size and morphology were investigated using transmission electron microscopy (TEM, JEOL 2100); elemental mapping was performed by EDXS analysis (JEOL ARM 200CF equipped with JEOL centurion 100). The specific surface area (SSA) and the porous properties of the photocatalysts were determined based on $\mathrm{N}_{2}$ adsorption-desorption isotherm at $-195.8^{\circ} \mathrm{C}$ using ASAP 2020 (Micromeritics Instrument Corporation, Norcross, GA, USA). Samples were degassed under reduced pressure for $10 \mathrm{~h}$ at $120{ }^{\circ} \mathrm{C}$ prior to analysis. The SSA was calculated according to the Brunauer-Emmett-Teller (BET) method from the linear part of the $\mathrm{N}_{2}$ adsorption isotherm. ${ }^{28}$ The total volume of pores $\left(V_{\text {total }}\right)$ was given at $p / p_{0}=0.998$. The volume of mesopores $\left(V_{\text {meso }}\right)$ and pore size distribution were analyzed according to the Barrett-Joyner-Halenda (BJH) method from the desorption branch of isotherm. ${ }^{29}$ The volume of micropores $\left(V_{\text {micro }}\right)$ was calculated from alpha-S plot. Particles size distribution in water suspensions was determined by laser light-scattering particle size analyzer (PSA) (Mastersizer 2000; Malvern Instruments Ltd., Malvern, Worchestershire, U.K.). Prior to measurements the powders were dispersed in distilled water, using a low-intensity ultrasonic bath, for $5 \mathrm{~min}$. The UV-Vis diffuse reflectance spectra (DRS) were recorded in the wavelength range $300-800 \mathrm{~nm}$ on an Evolution $600 \mathrm{UV}$-Vis spectrophotometer (Thermo Scientific), equipped with DRAEV-600 Diffuse Reflectance Accessory. Measurements were done on pellets $(\varnothing 6 \mathrm{~mm}, h \sim 1 \mathrm{~mm})$ prepared by pressing the powders (without any additives) by $P=300 \mathrm{MPa}$. The reflectance spectra were measured relative to $\mathrm{BaSO}_{4}$ as a reference sample. Photoluminescence (PL) spectra were recorded on Horiba Jobin Yvon Fluorolog FL3-22 spectrofluorometer using Xe lamp excitation (wavelength $325 \mathrm{~nm}$ ).

\subsection{Photocatalytic activity tests}

The photocatalytic activity of the samples was studied by the decolorization of methylene blue dye ( $\mathrm{MB}$, a cationic dye with chemical formula $\mathrm{C}_{16} \mathrm{H}_{18} \mathrm{ClN}_{3} \mathrm{~S} \cdot 3 \mathrm{H}_{2} \mathrm{O}$; $\mathrm{MB}$ shows an intense absorption peak at $665 \mathrm{~nm}$ ). Stock solution of $1000 \mathrm{ppm}$ was prepared by dissolving $1.0 \mathrm{~g}$ of methylene blue (Methylen blay B extra, E. Merck, Darmstadt, Germany) in 11 of distilled water. The MB solutions for photocatalytic activity experiments were prepared by diluting the stock solutions to the appropriate concentration.

In each of the experiments $100 \mathrm{mg}$ of a powder was mixed with $100 \mathrm{ml}$ of $\mathrm{MB}(10 \mathrm{ppm})$. Prior to illumination, the suspension was magnetically stirred for $1 \mathrm{~h}$ in a dark to establish an adsorption-desorption equilibrium. After the equilibrium had been established the concentration of $\mathrm{MB}$ was measured and taken as the initial concentration $C_{\mathrm{o}}$. During the illumination stirring was maintained to keep the mixture in suspension. At specific time intervals $3 \mathrm{ml}$ of aliquots was withdrawn and centrifuged $(8000 \mathrm{rpm}, 10 \mathrm{~min})$ to remove particles from solution before the absorbance measurement. The concentrations of the solutions were monitored by using a GBC Cintra UV-Vis spectrophotometer in the wavelength range of $300-800 \mathrm{~nm}$; concentration of the $\mathrm{MB}$ was calculated according to the absorbance value at $665 \mathrm{~nm}$.

The photocatalytic activity of the ingredients and $\mathrm{ZnO} / \mathrm{SnO}_{2}$ composites were tested under illumination of: (a) UV lamp (medium-pressure mercury vapor UV lamp, UVA region, Philips, $4 \times 15 \mathrm{~W}$ ), and (b) direct sunlight. The intensity of used UV light was $7 \mathrm{~mW} \mathrm{~cm}^{-2}$, as measured by YK-35UV light meter. All the experiments under direct sunlight illumination were done in time between 11:00 a.m. and 2:00 p.m. during the month of July 2015 and at ambient temperature $\left(25\right.$ to $\left.30^{\circ} \mathrm{C}\right)$.

Photocatalytic activity was also examined for the degradation of the pollutant that has no absorption in the visible range. The photocatalytic test was done on $\mathrm{ma}-\mathrm{ZnO} / \mathrm{SnO}_{2}$ for the degradation of phenol $\left(\mathrm{C}_{6} \mathrm{H}_{6} \mathrm{O}\right.$, Alpha Aesar, Karlsruhe, Germany) under direct sunlight illumination. The experimental conditions were the same as for the de-colorization of MB; $100 \mathrm{mg}$ of the powder was mixed with $100 \mathrm{ml}$ of phenol $(10 \mathrm{ppm})$. The phenol concentration during degradation was monitored by the UV-Vis spectrophotometer in the wavelength range of $200-400 \mathrm{~nm}$, and afterwards, calculated according to the maximum absorbance value at $210.5 \mathrm{~nm}$. The total organic carbon (TOC) was determined by the TOC Analyser Multi N/C (Analytik Jena, Austria).

\section{Results and discussion}

A thermal stability of ma- $\mathrm{ZnO} / \mathrm{SnO}_{2}$ composite was investigated by the TG-DTA analysis. The TG curve presented in Fig. 1 shows neglected weight loss of about $0.5 \%$ in the temperature range from 25 to $260{ }^{\circ} \mathrm{C}$, probably due to a small amount of surface water, ethanol and adsorbed gasses remained after the synthesis procedure. In the temperature range from 260 to about $900{ }^{\circ} \mathrm{C}$ a continuous weight gain exists accompanied with a wide exothermic peak in DTA curve. The total weight increase of about $5 \%$ is probably due to the solid state reaction between $\mathrm{ZnO}$ and $\mathrm{SnO}_{2}$ and formation of a new phase.

The TG-DTA results point to a high thermal stability of ma$\mathrm{ZnO} / \mathrm{SnO}_{2}$ composite up to $400{ }^{\circ} \mathrm{C}$. A considerable thermal stability of photocatalysts, without decomposition or phase transition, is highly desirable since allows their extensive 


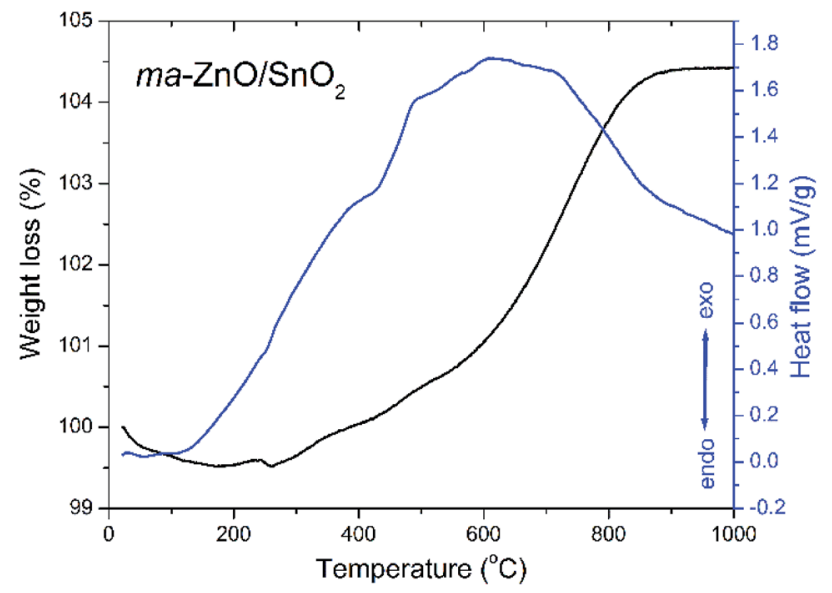

Fig. 1 TG-DTA plots of ma- $\mathrm{ZnO} / \mathrm{SnO}_{2}$ composite photocatalysts.

application. Besides, thermal stability is significant for photocatalysts recovery procedure, usually done by drying in an oven at $110^{\circ} \mathrm{C} .^{5,27}$

It is known that an annealing of $\mathrm{ZnO} / \mathrm{SnO}_{2}$ composites can considerably affect photocatalytic activity, mostly through point defect reparation and/or creation,,$^{\mathbf{4 , 2 0 , 3 0 , 3 1}}$ whereby the annealing temperature has a large impact. Having in mind results of the TG-DTA analysis we chose to anneal ma- $\mathrm{ZnO} / \mathrm{SnO}_{2}$ composite at two different temperatures: at $400{ }^{\circ} \mathrm{C}$, since up to this temperature adsorbed moisture and gasses will be desorbed while solid state reaction will not be started; and at $700{ }^{\circ} \mathrm{C}$, as the temperature at which solid state reaction take place and is not completed.

XRD patterns presented in Fig. 2(a) indicate a high crystallinity of all examined samples. All the diffraction peaks in the pattern of pristine $\mathrm{ZnO}$ can be indexed to wurtzite-type structure with hexagonal phase ( $P 6_{3} m c$ space group; JCPDS no. 89-0510), while the diffraction peaks in pattern of pristine $\mathrm{SnO}_{2}$ belong to cassiterite with tetragonal phase $\left(\mathrm{P}_{2} / \mathrm{mnm}\right.$ space group; JCPDS no. 88-0287). Composite powder $\mathrm{ma}-\mathrm{ZnO} / \mathrm{SnO}_{2}$ is consisted of hexagonal $\mathrm{ZnO}$ and tetragonal $\mathrm{SnO}_{2}$ phases, without any other crystal phases. Since there is no reflection of any iron based phases, it can be confirmed that contamination from milling media is below the detection limit of the XRD technique. According to the XRD pattern, the $\mathrm{ZnO} / \mathrm{SnO}_{2}-400$ composite has the same phase composition as $\mathrm{ma}-\mathrm{ZnO} / \mathrm{SnO}_{2}$. However, in the XRD pattern of the $\mathrm{ZnO} / \mathrm{SnO}_{2}-700$ composite several additional reflections appeared, indicating the existence of an additional phase. To more precise identify a new phase, broad band composed of (310) and (103) reflections (belonging to $\mathrm{SnO}_{2}$ and $\mathrm{ZnO}$, respectively) of $\mathrm{ZnO} / \mathrm{SnO}_{2}-700$ were examined by a deconvolution; Fig. 2(b) shows the expanded and deconvoluted region between 61 and $642 \theta$ angles. After the deconvolution, a new reflection at $62.52 \theta$ angle can be clearly seen. It is find that all the additional reflections (marked by a purple circle in Fig. 2(a)), including one at $62.52 \theta$ angle, belong to $\mathrm{Zn}_{2} \mathrm{SnO}_{4}$ (JCPDS no. 74-2184). The development of the $\mathrm{Zn}_{2} \mathrm{SnO}_{4}$ phase correlates with the weight gain and a large exothermic peak as observed by TG-DTA.
It is observed that addition of the $\mathrm{SnO}_{2}$ and increases of the annealing temperature provoke a slight shift of $\mathrm{ZnO}$ diffraction peaks toward the higher $2 \theta$ angles; in Fig. 2(c) shift of the (101) peak is shown as an illustrative example. The shift of diffraction peaks toward the higher $2 \theta$ angles is caused by a decrease of the interplanar spacing, i.e. by a reduction of the lattice parameters (see Table 1). In the cases of $\mathrm{ZnO} / \mathrm{SnO}_{2}-400$ and $\mathrm{ZnO} / \mathrm{SnO}_{2}-700$ decrease of the interplanar spacing may result from interfacial substitution of zinc sites in $\mathrm{ZnO}$, with a crystal radius of $\mathrm{Zn}^{2+}$ in coordination IV equal to $0.74 \AA{ }^{32}$ by $\mathrm{Sn}^{4+}$, with a crystal radius in coordination IV equal to $0.69 \AA{ }^{32}$ that were diffused from $\mathrm{SnO}_{2}$ during the annealing process. This process yields a small quantity of $\mathrm{Zn}_{2} \mathrm{SnO}_{4}$.

The refined unit cell parameters for all the examined powders are listed in Table 1 . It should be stressed that parameters for pristine $\mathrm{ZnO}$ and $\mathrm{SnO}_{2}$ powders are in good agreement with those reported in corresponding JCPDS cards (89-0510 and 88-0287, respectively). The refined unit cell parameters shows that mechanical milling slightly reduces $\mathrm{ZnO}$ crystal lattice, while crystal lattice of $\mathrm{SnO}_{2}$ stay stable. Additional annealing provokes further reduction of $\mathrm{ZnO}$ crystal lattice and trigger shrinkage of tin oxide unit cell, too. The calculated values of crystallite sizes in specific crystallographic directions ([100] and [002] for $\mathrm{ZnO}$, and [110] and [101] for $\mathrm{SnO}_{2}$ ) and average crystallite size are listed in Table 1 . The results implicate a slight decrease of zinc oxide average crystallite size after $2 \mathrm{~h}$ of mechanical activation, retaining of that size during annealing at $400{ }^{\circ} \mathrm{C}$, and promoted growth at $700{ }^{\circ} \mathrm{C}$.

As a complementary to the XRD, ATR/FT-IR and Raman spectroscopy studies were used for an analysis of the photocatalysts crystal structure and to determine effects of the mechanical milling and the annealing.

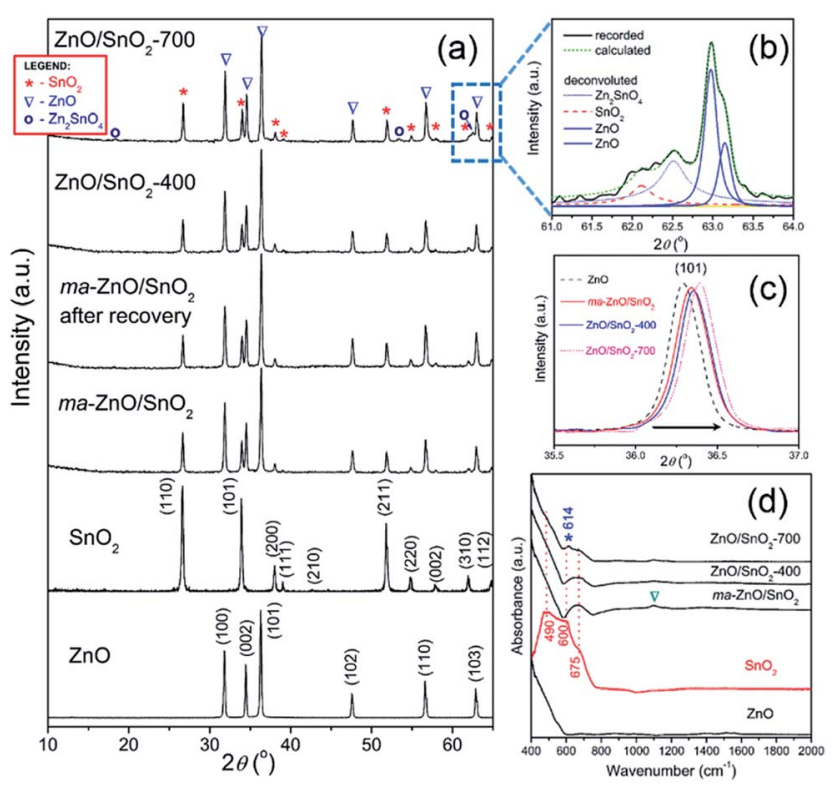

Fig. 2 (a) XRD patterns of pristine metal oxides and photocatalysts particles, (b) expanded and deconvoluted 61 to $64^{\circ} 2 \theta$ region of $\mathrm{ZnO} /$ $\mathrm{SnO}_{2}-700$, (c) shifting of the (101) reflection of $\mathrm{ZnO}$, and (d) ATR/FT-IR spectra of pristine metal oxides and photocatalysts particles. 
Table 1 The values of average crystallite size, crystallite sizes in specific crystallographic directions, and the unit cell parameters with standard deviations

\begin{tabular}{|c|c|c|c|c|c|c|c|c|c|c|}
\hline \multirow[b]{2}{*}{ Sample } & \multirow[b]{2}{*}{$D_{\mathrm{ZnO}}(\mathrm{nm})$} & \multirow[b]{2}{*}{$D_{\mathrm{SnO}_{2}}(\mathrm{~nm})$} & \multirow[b]{2}{*}{$D_{\mathrm{Zn}_{2} \mathrm{SnO}_{4}}(\mathrm{~nm})$} & \multirow[b]{2}{*}{$D_{\text {composite }}(\mathrm{nm})$} & \multicolumn{2}{|c|}{$\mathrm{ZnO}(\mathrm{nm})$} & \multicolumn{2}{|c|}{$\mathrm{SnO}_{2}(\mathrm{~nm})$} & \multicolumn{2}{|c|}{$\begin{array}{l}\text { Unit cell parameters } \\
(\AA)\end{array}$} \\
\hline & & & & & {$[100]$} & [002] & [110] & [101] & $a=b$ & $c$ \\
\hline $\mathrm{ZnO}$ & $39.14 \pm 2.09$ & - & - & - & 42.13 & 46.66 & - & - & $3.2477(4)$ & $5.2044(2)$ \\
\hline $\mathrm{SnO}_{2}$ & - & $34.94 \pm 3.09$ & - & - & - & - & 35.75 & 39.87 & $4.7353(5)$ & $3.1867(4)$ \\
\hline $\mathrm{ma}-\mathrm{ZnO} / \mathrm{SnO}_{2}$ & $36.74 \pm 2.15$ & $36.11 \pm 4.59$ & - & $36.40 \pm 2.56$ & 37.89 & 43.45 & 48.21 & 45.00 & $\begin{array}{l}3.2470(6)^{a} \\
4.7354(7)^{b}\end{array}$ & $\begin{array}{l}5.2037(3) \\
3.1867(3)\end{array}$ \\
\hline $\mathrm{ZnO} / \mathrm{SnO}_{2}-700$ & $44.33 \pm 3.67$ & $40.12 \pm 3.58$ & $14.87 \pm 3.30$ & $37.23 \pm 3.49$ & 43.32 & 42.96 & 42.65 & 46.05 & $\begin{array}{l}3.2437(3)^{a} \\
4.7347(5)^{b}\end{array}$ & $\begin{array}{l}5.1901(2) \\
3.1860(4)\end{array}$ \\
\hline
\end{tabular}

${ }^{a}$ Data for $\mathrm{ZnO}$ fraction. ${ }^{b}$ Data for $\mathrm{SnO}_{2}$ fraction.

According to the group theory predictions hexagonal $\mathrm{ZnO}$ crystals with wurtzite crystal structure and $C_{6 \mathrm{v}}{ }^{4}$ symmetry have eight sets of phonon normal modes at the $T$ point, represented as $\Gamma=2 \mathrm{~A}_{1}+2 \mathrm{E}_{1}+2 \mathrm{~B}_{1}+2 \mathrm{E}_{2}$. Among them, one set of $\mathrm{A}_{1}$ and $\mathrm{E}_{1}$ modes are acoustic, while the remaining ones are optical modes, to be precise, $\Gamma_{\mathrm{opt}}=\mathrm{A}_{1}+2 \mathrm{~B}_{1}+\mathrm{E}_{1}+2 \mathrm{E}_{2}$. The $\mathrm{A}_{1}$ and $\mathrm{E}_{1}$ are both Raman and infrared active, $\mathrm{E}_{2}$ is Raman active only, whereas $B_{1}$ is inactive i.e. silent mode. Moreover, the $A_{1}$ and $E_{1}$ modes are polar and split into transverse optical (TO) and longitudinal optical (LO) components. The $\mathrm{E}_{2}$ mode is consisted of two modes, of low and high frequency phonons $\left(\mathrm{E}_{2}^{\text {low }}\right.$ and $\mathrm{E}_{2}^{\text {high }}$ ), associated with the vibration of the heavy $\mathrm{ZnO}$ sublattice and oxygen atoms, respectively. Tetragonal $\mathrm{SnO}_{2}$ with rutile crystal structure and $D_{4 \mathrm{~h}}{ }^{14}$ symmetry has eleven sets of phonon normal modes represented by $\Gamma=1 \mathrm{~A}_{1 \mathrm{~g}}+1 \mathrm{~A}_{2 \mathrm{~g}}+1 \mathrm{~A}_{2 \mathrm{u}}+1 \mathrm{~B}_{1 \mathrm{~g}}+$ $1 B_{2 g}+2 B_{1 u}+1 E_{g}+3 E_{u}$. Among these phonons $A_{1 g}, B_{1 g}, B_{2 g}$ and $\mathrm{E}_{g}$ are Raman active, while $\mathrm{A}_{2 \mathrm{u}}$ and $\mathrm{E}_{\mathrm{u}}$ are infrared active modes. $^{33,34}$

The ATR/FT-IR spectra of investigated samples are shown in Fig. 2(d). The main characteristic in the spectrum of $\mathrm{ZnO}$ particles is peak in the region from 400 to $600 \mathrm{~cm}^{-1}$, attributed to $\mathrm{Zn}-\mathrm{O}$ vibrations in $\mathrm{ZnO}$ lattice. ${ }^{35}$ The spectrum of $\mathrm{SnO}_{2}$ shows a broad band between 400 and $760 \mathrm{~cm}^{-1}$ attributed to $\mathrm{E}_{\mathrm{u}}$ mode of anti-symmetric Sn-O stretching vibrations., ${ }^{3,36}$ The mathematical deconvolution of this broad band yields three Gaussian peaks centered at 491.5, 603 and $675 \mathrm{~cm}^{-1}$; this result is in accordance with the group theory which predict triple degenerative $\mathrm{E}_{\mathrm{u}}$ mode. The spectrum of ma- $\mathrm{ZnO} / \mathrm{SnO}_{2}$ shows two main band, first one is in the region from 400 to $600 \mathrm{~cm}^{-1}$ due to $\mathrm{Zn}-\mathrm{O}$ vibrations and second one in the range $580-750 \mathrm{~cm}^{-1}$ attributed to $\mathrm{Sn}-\mathrm{O}$ stretching vibrations. It is worth to note that mechanical milling of $\mathrm{ZnO} / \mathrm{SnO}_{2}$ mixture leads to almost $180 \mathrm{~cm}^{-1}$ blue shift of $E_{u}$ mode. Previously have been shown that a blue shift of $\mathrm{E}_{\mathrm{u}}$ mode occurs when tin oxide particles are reduced; ${ }^{33,34}$ in the case of $\mathrm{ma}-\mathrm{ZnO} / \mathrm{SnO}_{2}$ sample this statement is further confirmed by FESEM analysis, results are discussed later in the text. Furthermore, small band which arouses near $1100 \mathrm{~cm}^{-1}$ (indicated by triangle) is due to $\mathrm{C}-\mathrm{O}$ stretching vibrations from $\mathrm{CO}_{2}$ adsorbed at the particles surface. The spectrum of $\mathrm{ZnO} / \mathrm{SnO}_{2}-400$ is almost the identical as ma- $\mathrm{ZnO} /$
$\mathrm{SnO}_{2}$ one, actually, without $\mathrm{C}-\mathrm{O}$ vibrations since particles have been degassed during annealing at $400^{\circ} \mathrm{C}$. New small and sharp peak at $614 \mathrm{~cm}^{-1}$ (indicated by asterisk) appears in the spectrum of $\mathrm{ZnO} / \mathrm{SnO}_{2}-700$; it belongs to $\mathrm{E}_{\mathrm{u}}$ mode which is assigned to the surface phonons, thus, any change of the band implicates modifications of the surface structure. ${ }^{33}$ In this case, during annealing at $700{ }^{\circ} \mathrm{C}$ interfacial cations diffuse producing the defects on the particles surface, also modifying the local symmetry in the crystal. Certainly, the band at $614 \mathrm{~cm}^{-1}$ can be indication of $\mathrm{Zn}-\mathrm{O}-\mathrm{Sn}$ vibrations, confirming the development of $\mathrm{Zn}_{2} \mathrm{SnO}_{4}$.

Fig. 3 shows Raman spectra of the pristine metal oxides and the composites. The vibrational modes in spectrum of $\mathrm{ZnO}$ are assigned as: an intensive peak near $100 \mathrm{~cm}^{-1}$ is ascribed to the vibrations of the zinc sublattice in $\mathrm{ZnO} ;{ }^{37,38}$ the peak around $200 \mathrm{~cm}^{-1}$ is due deformation mode, while the peaks at 330 and $379 \mathrm{~cm}^{-1}$ are due to the second-order vibration mode $\mathrm{E}_{2 \mathrm{H}}-\mathrm{E}_{2 \mathrm{~L}}$ and the transverse-optical mode $\mathrm{A}_{1}$ (TO), respectively. ${ }^{38}$ A sharp and intensive peak near $440 \mathrm{~cm}^{-1}$ is due to $E_{2 \mathrm{H}}$ mode which is

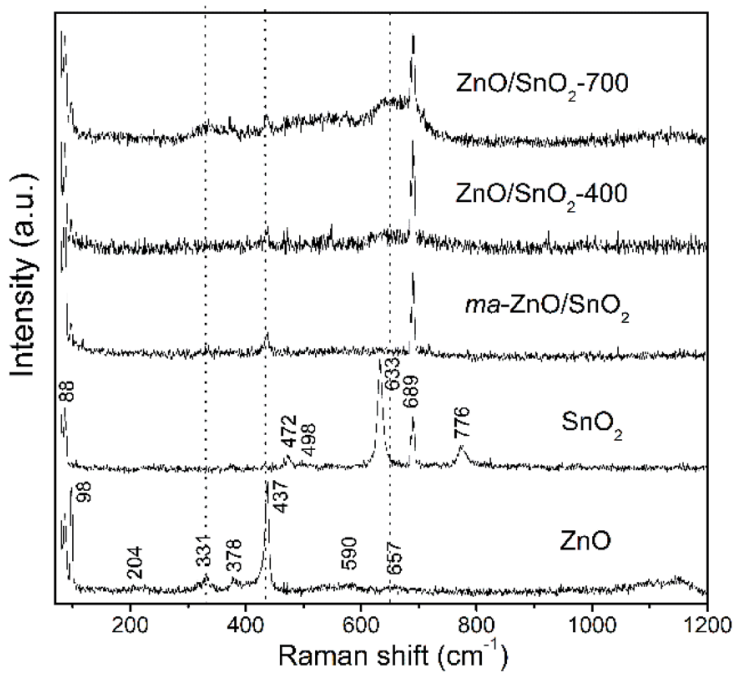

Fig. 3 Raman spectra of pristine metal oxides and photocatalysts particles. 
related to vibration of oxygen attached to zinc atoms in the tetrahedral coordination. ${ }^{38}$ The strong $\mathrm{E}_{2 \mathrm{H}}$ mode indicates high crystallinity which is in good correlation with the XRD data for the pristine $\mathrm{ZnO}$ powder. The peak at 590 is attributed to $\mathrm{A}_{1}(\mathrm{LO})$ and $\mathrm{E}_{1}$ (LO) modes, while peak at $657 \mathrm{~cm}^{-1}$ represents combination of acoustic and optical modes (TA $+\mathrm{LO}$ ). These two peaks revealed the existence of lattice defects, in particular, oxygen vacancies and zinc interstitials. ${ }^{38}$ It is known that longitudinal optical modes $\mathrm{A}_{1}$ (LO) and $\mathrm{E}_{1}$ (LO) are evident only when the $c$-axis of the wurtzite crystal structure is parallel to the particles surface ${ }^{39}$ Existence of these peaks in Raman spectra of pristine $\mathrm{ZnO}$ implicate to rod-shaped particles (this statement is confirmed by FESEM analysis, results are discussed later in the text). Wide band in wavenumber region $1090-1150 \mathrm{~cm}^{-1}$ is attributed to optical overtone $2 \mathrm{LO}$, actually to $2 \mathrm{~A}_{1}(\mathrm{LO})$ and $2 \mathrm{E}_{1}$ (LO). The Raman spectrum of tin oxide particles shows the peaks centered at 474,633 , and $776 \mathrm{~cm}^{-1}$ which are ascribed to the $\mathrm{E}_{\mathrm{g}}, \mathrm{A}_{1 \mathrm{~g}}$, and $\mathrm{B}_{2 \mathrm{~g}}$ modes of $\mathrm{SnO}_{2}$, respectively. Peaks at 474 , 631 and $776 \mathrm{~cm}^{-1}$ are related to the expansion and contraction vibration modes of $\mathrm{Sn}-\mathrm{O}$ bonds in the rutile crystal structure. ${ }^{34}$ Peaks at 498 and $689 \mathrm{~cm}^{-1}$ belong to infrared-active modes $\mathrm{A}_{2 \mathrm{u}}$ (TO) and $A_{2 u}(\mathrm{LO})$, respectively. As it is indicated above, $A_{2 u}$ mode is assigned to the surface phonons; obviously for pristine $\mathrm{SnO}_{2}$ sample used in this work the surface atoms represent a significant fraction of atoms.

As can be seen from the Raman spectrum of ma- $\mathrm{ZnO} / \mathrm{SnO}_{2}$, the peaks of the $\mathrm{SnO}_{2}$ phase are dominant while those of the ZnO significantly decrease after mechanical milling. This decrease of $\mathrm{ZnO}$ peaks intensities is due to the reduction of the zinc oxide crystallinity, related with a large amount of surface defects introduced by mechanical milling. ${ }^{15}$ Vanishing of the tin oxide peak at $776 \mathrm{~cm}^{-1}$ in the Raman spectra of the composites is due to significant decreases of $\mathrm{SnO}_{2}$ particles sizes after milling (this assumption is further confirmed with results of FESEM and HRTEM analyses). Besides, the tin oxide peak at $663 \mathrm{~cm}^{-1}$ slightly increases and becomes broader in the spectra of annealed composites as compared to spectrum of ma- $\mathrm{ZnO} /$ $\mathrm{SnO}_{2}$. This can be attributed to the high-temperature induced substitution of tin cations into the $\mathrm{ZnO}$ structure and formation of a small amount of $\mathrm{Zn}_{2} \mathrm{SnO}_{4}{ }^{34}$ In order to compensate positive charge, the substitution of $\mathrm{Zn}^{2+}$ for $\mathrm{Sn}^{4+}$ ions would be accompanied by formation of more $V_{\mathrm{O}}$; that is confirmed in the spectrum of $\mathrm{ZnO} / \mathrm{SnO}_{2}-700$ composites, where the intensity and width of the peaks at 330 and $657 \mathrm{~cm}^{-1}$ increases pointing to increase of $V_{\mathrm{O}}$ and $\mathrm{Zn}_{\mathrm{i}}$ lattice defects. Thus, evolution of peaks in Raman spectra of $\mathrm{ZnO} / \mathrm{SnO}_{2}$ composites confirmed that the relative concentration ratio of bulk defects to surface defects is strongly influenced by processing approach.

Effects of the mechanical milling and successive annealing on particles morphology, size distribution and texture properties were analyzed by scanning electron microscopy, particle size analyzer and nitrogen adsorption-desorption isotherm, respectively.

FESEM images of pristine metal oxides and prepared photocatalysts particles are shown in Fig. 4 . As can be seen the pristine ZnO particles are mainly consisted of irregular hexagonal rod-shapes with a smooth crystal facets; their average diameter is about $95 \mathrm{~nm}$ while the average length is about $180 \mathrm{~nm}$. The pristine $\mathrm{SnO}_{2}$ powder is consisted of coarse polygonal grains, with average size of about $600 \mathrm{~nm}$, which are organized in agglomerates of about $2 \mu \mathrm{m}$ sizes. After $2 \mathrm{~h}$ of milling significant reduction of $\mathrm{ZnO}$ particles or a change of their shape are not observed. It can be noticed that after milling surface of ZnO crystals is no more flat but is covered with a small spheroidal particles of tin oxide. Thus, during the milling soft agglomerates of $\mathrm{SnO}_{2}$ particles are broken;

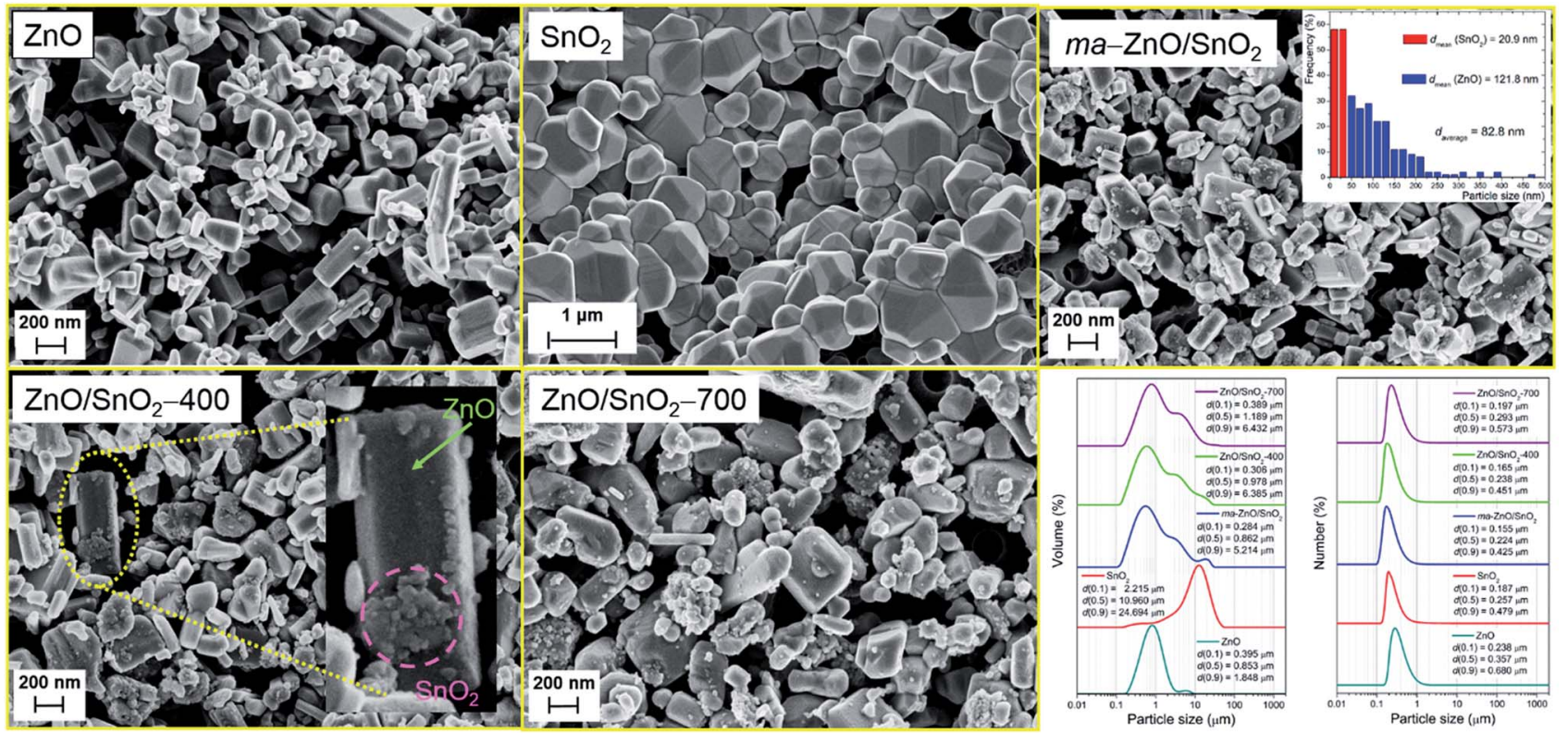

Fig. 4 FESEM images of pristine metal oxides and photocatalysts particles; particle size distribution (based on volume and on number) determined by laser diffraction from water suspensions (bottom-right). 
furthermore, primary particles are considerably reduced. The average particle size of $\mathrm{ma}-\mathrm{ZnO} / \mathrm{SnO}_{2}$ composite is estimated from the recorded micrograph by measuring the largest dimension of more than 300 particles; a particle size distribution is given as the micrograph inset. It should be highlighted that in this case computing program (SemAfore digital slow scan image recording system, version 5.21 demo; JEOL, Tokyo, Japan) is used for estimation of the particle size distribution since it allows distinguishing of $\mathrm{ZnO}$ and $\mathrm{SnO}_{2}$ fractions in the mixture. The average particle size of $\mathrm{ma}-\mathrm{ZnO} / \mathrm{SnO}_{2}$ composite is about $83 \mathrm{~nm}$, among them $\mathrm{ZnO}$ crystals are $\sim 122 \mathrm{~nm}$ in average, while the mean size of $\mathrm{SnO}_{2}$ particles is $\sim 21 \mathrm{~nm}$. According to the micrographs it can be concluded that further annealing have no significant influence on average particle size.

The BET results of the specific surface area and pore structure of examined samples are depicted in Table 2. BET surface area of pristine $\mathrm{ZnO}$ is $5.75 \mathrm{~m}^{2} \mathrm{~g}^{-1}$; total volume of pores is $0.0163 \mathrm{~cm}^{3} \mathrm{~g}^{-1}$ with more than $90 \%$ of mesopores with diameter between 2 and $50 \mathrm{~nm}$. The BET results show that pristine $\mathrm{SnO}_{2}$ powder is not porous and have low surface area, these values are too small to be measured with very sensitive equipment used for characterization. The BET surface area of ma$\mathrm{ZnO} / \mathrm{SnO}_{2}$ composite is $6.55 \mathrm{~m}^{2} \mathrm{~g}^{-1}$, while the total volume of pores is $0.0229 \mathrm{~cm}^{3} \mathrm{~g}^{-1}$; both values were slightly higher as compared to pristine metal oxides, implicating profound effects of mechanical treatment especially on commercial $\mathrm{SnO}_{2}$ powder. Annealing at 400 and $700{ }^{\circ} \mathrm{C}$ has neglected influence on texture properties of the composite.

The particles size distributions and characteristics parameters, based on volume and number, determined by a laser diffraction scattering, are presented in the right-bottom part of the Fig. 4 . The distribution results based on volume show that average particle sizes of pristine $\mathrm{ZnO}$ and $\mathrm{SnO}_{2}$ in water dispersion are 0.85 and $10.96 \mu \mathrm{m}$, respectively. Obviously the milling has not significant effects on $\mathrm{ZnO}$ particles but a total effect is profound since $\mathrm{SnO}_{2}$ agglomerates have been broken. Actually, the most important effect of milling is on tin oxide $d_{\mathrm{v}}(0.9)$ which falls from 24.7 to $5.2 \mu \mathrm{m}$. Further annealing slightly increase particle sizes, because particles start to overconnect through sintering procedure. While the distribution over volume describe large particles those occupy a small amount of the sample, the insight in the statistically predominant particles is given by distribution over number.
The distribution over number shows similar trend as the volume one; particles have a high degree of uniformity and a relatively narrow span values. Besides, PSD shows that particles are in the range between 150 (for $d_{\mathrm{N}}(0.1)$ ) and $680 \mathrm{~nm}$ (for $\left.d_{\mathrm{N}}(0.9)\right)$. Since the purpose of this photocatalysts is their usage in water environment, for purification, decolorization, electrolysis, etc., it is very important to separate them from water after usage, either for the sake of recycling or to prevent further water contamination. Thus, $d_{\mathrm{N}}(0.1)$, which describes the smallest particles of the photocatalysts in water dispersion, is an important characteristics which determine the way of their separation. In this case, catalysts can be removed from the liquid phase by filtration through a (cellulose acetate, nylon, etc.) membrane with pore size of $0.10 \mu \mathrm{m}$.

TEM and HRTEM images presented in Fig. 5 provide direct information about size and shape of the composite particles after annealing at 400 and $700{ }^{\circ} \mathrm{C}$. As it is clearly illustrated at low magnified TEM images (Fig. 5, left), both samples are mainly composed of elongated $\mathrm{ZnO}$ grains with longer edge of about $200 \mathrm{~nm}$ (sporadically grains with $500 \mathrm{~nm}$ length are observed) and much smaller nanosized grains of $\mathrm{SnO}_{2}$. While nanosized $\mathrm{SnO}_{2}$ grains are present in the form of loosely connected agglomerates in $\mathrm{ZnO} / \mathrm{SnO}_{2}-700$ sample, Fig. 5(b), their presence in $\mathrm{ZnO} / \mathrm{SnO}_{2}-400$ sample is revealed at the surface of the ZnO grains in the HRTEM image, Fig. 5(a). A higher magnification pointed out that $\mathrm{SnO}_{2}$ particles sized around $20 \mathrm{~nm}$ are single crystallized; marked periodical structures belong to the (110) plane of cassiterite (JCPDS no. 88-0287) which persistence in this sample is confirmed by XRD analysis. Furthermore, the interplanar distance of $1.908 \AA$ associated with the (102) plane of hexagonal wurtzite-type structure is clearly distinguished in a quite larger $\mathrm{ZnO}$ grain (FFT inset presented at Fig. 5), indicating formation of the $\mathrm{ZnO} / \mathrm{SnO}_{2}$ heterojunction in this sample. The annealing at higher temperature increases formation of $\mathrm{SnO}_{2}$ agglomerates in $\mathrm{ZnO} /$ $\mathrm{SnO}_{2}-700$ sample. Despite it, a small amount of $\mathrm{SnO}_{2}$ nanocrystallites dispersed over larger $\mathrm{ZnO}$ grains is still notable in HRTEM image, Fig. 5(b). The corresponding elemental mapping (EDXS analysis), Fig. 6 and 7, verifies phase designation of particles based on HRTEM/FFT analysis. Moreover, it highlights that $\mathrm{SnO}_{2}$ nanocrystallites are present on the surface of much larger $\mathrm{ZnO}$ particles in both samples, but their spreading is more uniform in $\mathrm{ZnO} / \mathrm{SnO}_{2}-700$ sample, Fig. 7. The

Table 2 Effects of milling and annealing on SSA, volume and size of pores, and average particle size determined by PSA

\begin{tabular}{|c|c|c|c|c|c|c|c|c|c|}
\hline \multirow[b]{2}{*}{ Sample } & \multirow[b]{2}{*}{$S_{\mathrm{BET}}^{a}\left(\mathrm{~m}^{2} \mathrm{~g}^{-1}\right)$} & \multirow[b]{2}{*}{$V_{\text {total }}^{b}\left(\mathrm{~cm}^{3} \mathrm{~g}^{-1}\right)$} & \multirow[b]{2}{*}{$V_{\text {meso }}^{c}\left(\mathrm{~cm}^{3} \mathrm{~g}^{-1}\right)$} & \multirow[b]{2}{*}{$V_{\text {micro }}{ }^{d}\left(\mathrm{~cm}^{3} \mathrm{~g}^{-1}\right)$} & \multirow[b]{2}{*}{$r_{\mathrm{av}}{ }^{e}(\mathrm{~nm})$} & \multirow[b]{2}{*}{$d_{\mathrm{V}}(0.5)_{\mathrm{PSA}}^{f}(\mu \mathrm{m})$} & \multirow[b]{2}{*}{$d_{\mathrm{N}}(0.5)_{\mathrm{PSA}^{g}}^{g}(\mu \mathrm{m})$} & \multicolumn{2}{|l|}{$E_{\mathrm{bg}}$} \\
\hline & & & & & & & & $(\mathrm{eV})$ & $(\mathrm{nm})$ \\
\hline $\mathrm{ZnO}$ & 5.75 & 0.0163 & 0.0154 & 0.0020 & 13.64 & 0.853 & 0.357 & 3.26 & 380 \\
\hline $\mathrm{SnO}_{2}$ & - & - & - & - & - & 10.960 & 0.257 & 3.55 & 349 \\
\hline $\mathrm{ma}-\mathrm{ZnO} / \mathrm{SnO}_{2}$ & 6.55 & 0.0229 & 0.0212 & 0.0023 & 24.53 & 0.862 & 0.224 & 3.21 & 386 \\
\hline $\mathrm{ZnO} / \mathrm{SnO}_{2}-400$ & 6.22 & 0.0265 & 0.0252 & 0.0021 & 18.71 & 0.978 & 0.238 & 3.21 & 386 \\
\hline $\mathrm{ZnO} / \mathrm{SnO}_{2}-700$ & 6.15 & 0.0249 & 0.0237 & 0.0016 & 18.87 & 1.189 & 0.293 & 3.18 & 390 \\
\hline
\end{tabular}

${ }^{a} S_{\mathrm{BET}}$ - BET specific surface area. ${ }^{b} V_{\text {total }}$ - total pore volume. ${ }^{c} V_{\text {meso }}-$ volume of mesopores $(2-50 \mathrm{~nm}) .{ }^{d} V_{\text {micro }}-$ volume of micropores $(<2 \mathrm{~nm}) .{ }^{e} r_{\mathrm{av}}$ - BJH adsorption average pore diameter. ${ }^{f} d_{\mathrm{v}}(0.5)_{\mathrm{PSA}}$ - average particle size (based on volume) determined by particle size analyzer (PSA). $\left.{ }^{g} d_{\mathrm{N}}(0.5)\right)_{\mathrm{PSA}}$ - average particle size (based on number) determined by particle size analyzer (PSA). 


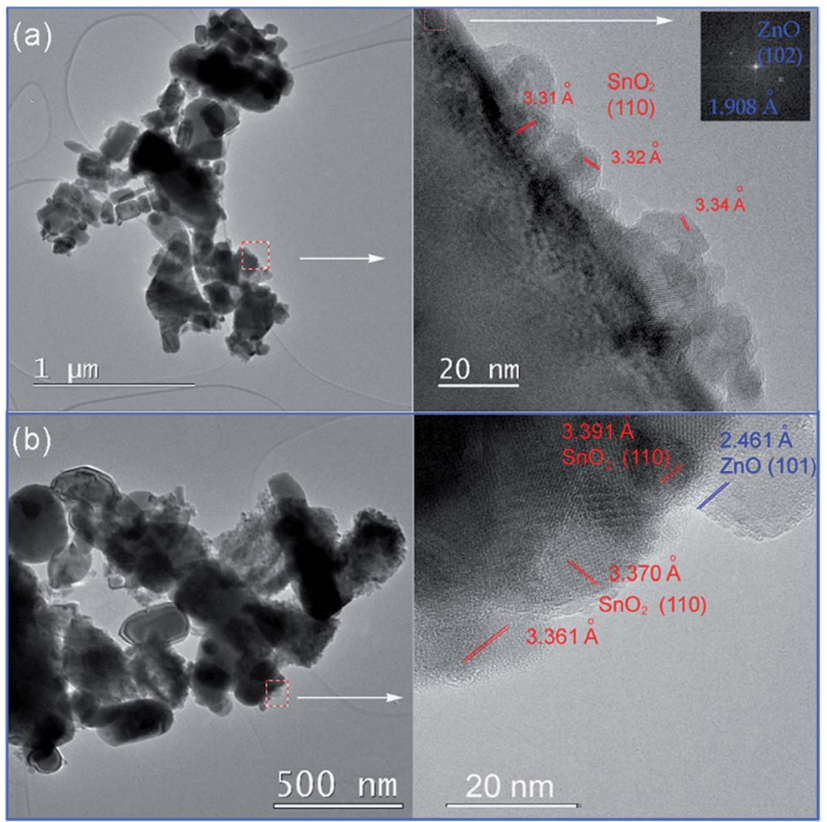

Fig. 5 TEM (left), and HRTEM (right) with marked interplanar distances of: (a) $\mathrm{ZnO} / \mathrm{SnO}_{2}-400$ powder; $F F T$ of $\mathrm{ZnO}$ phase is given as an inset, and (b) $\mathrm{ZnO} / \mathrm{SnO}_{2}-700$ powder.

driving force for such self-assembling originates from the hightemperature solid state diffusion.

The optical properties of pristine $\mathrm{ZnO}$ and $\mathrm{SnO}_{2}$ powders, also, the effects of mechanical milling and subsequent annealing on the capacity of visible light absorption and band gap energy of photocatalysts were examined by UV-Vis DRS, plots are presented in Fig. 8. Diffuse reflectance spectra, Fig. 8(a), reveal characteristic $R$ curves for all the examined powders. It can be observed that the absorption edge for $\mathrm{SnO}_{2}$ is near $300 \mathrm{~nm}$, while for all the other powders is near $380 \mathrm{~nm}$. Besides, metal oxides have similar reflectance in the visible light region, between 85 and $95 \%$, which is much larger than reflectance of composite powders. The lowest reflectance in the
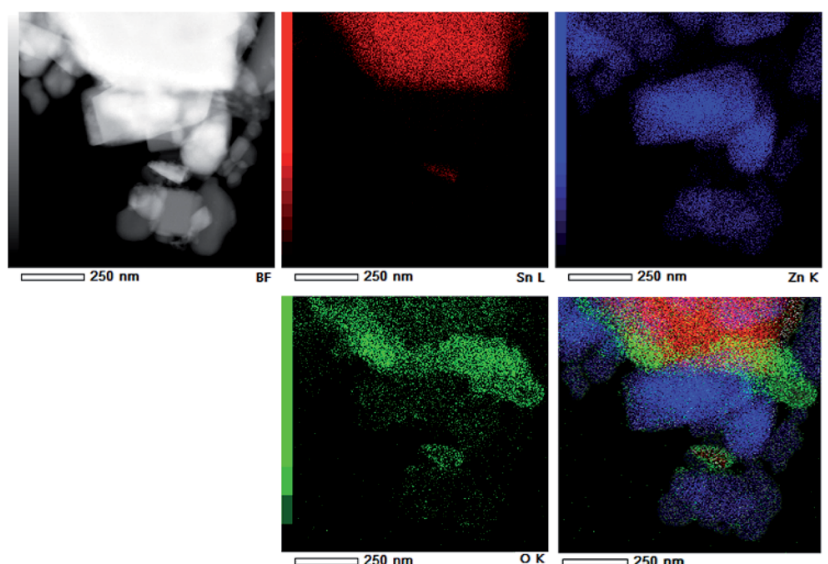

Fig. 6 EDXS mapping of $\mathrm{Zn}, \mathrm{Sn}$, and $\mathrm{O}$ concentration in $\mathrm{ZnO} / \mathrm{SnO}_{2}$ 400 powder.
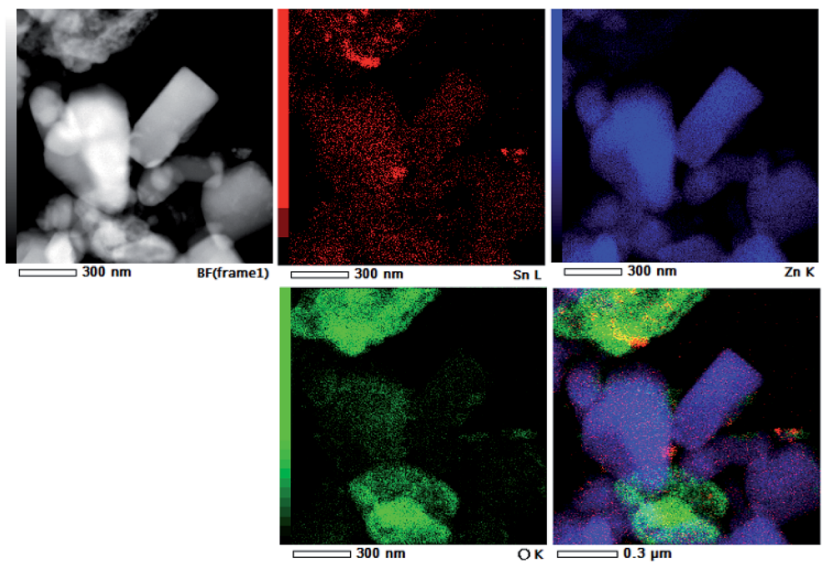

Fig. 7 EDXS mapping of $\mathrm{Zn}, \mathrm{Sn}$, and $\mathrm{O}$ concentration in $\mathrm{ZnO} / \mathrm{SnO}_{2}-$ 700 powder.

spectral region $380-800 \mathrm{~nm}$ shows $\mathrm{ma}-\mathrm{ZnO} / \mathrm{SnO}_{2}$ and $\mathrm{ZnO} / \mathrm{SnO}_{2}-400$ composites, while $\mathrm{ZnO} / \mathrm{SnO}_{2}-700$ has the lowest reflectance (below $25 \%$ ) in the range $380-500 \mathrm{~nm}$, with further tendency to increase up $45 \%$ between 500 and $800 \mathrm{~nm}$. It should be highlighted that the absorption capacity of composites is almost three times improved in comparison with pristine metal oxides. The improved absorption capacity of composite may be attributed to a large number of surface defects introduced by mechanical activation; on this way, profound influence of mechanical milling on optical properties is confirmed. (Here, the absorption capacity can be correlated with reflectance since the measurements were done on pellets with thickness of $1 \mathrm{~mm}$, thus, transparence could be neglected).

The direct band gap energies $\left(E_{\mathrm{bg}}\right)$ of the photocatalysts were determined from the plots of Kubelka-Munk function versus photon energy (eV). ${ }^{36,40}$ First of all, the diffuse reflectance $R$ is correlated to the Kubelka-Munk function $F(R)$ by relation $F(R)=$ $\left(1-R^{2}\right) /(2 R)$; then, band gap energies were estimated from a plot of $(F(R) \cdot h \nu)^{2}=f(h \nu)$ as intercepts obtained by the extrapolation of the linear part of the curves to $(F(R) \cdot h \nu)^{2}=0$, as it is shown in Fig. 8(b). Determined $E_{\mathrm{bg}}$ values are $3.55 \mathrm{eV}$ for $\mathrm{SnO}_{2}, 3.26 \mathrm{eV}$ for $\mathrm{ZnO}, 3.21 \mathrm{eV}$ for $\mathrm{ma}-\mathrm{ZnO} / \mathrm{SnO}_{2}$ and $\mathrm{ZnO} / \mathrm{SnO}_{2}-400$ composites, and $3.18 \mathrm{eV}$ for $\mathrm{ZnO} / \mathrm{SnO}_{2}-700$.

The red shift of ma- $\mathrm{ZnO} / \mathrm{SnO}_{2}$ band gap energy of $0.05 \mathrm{eV}$ as compared to pristine $\mathrm{ZnO}$ can be attributed to surface defects
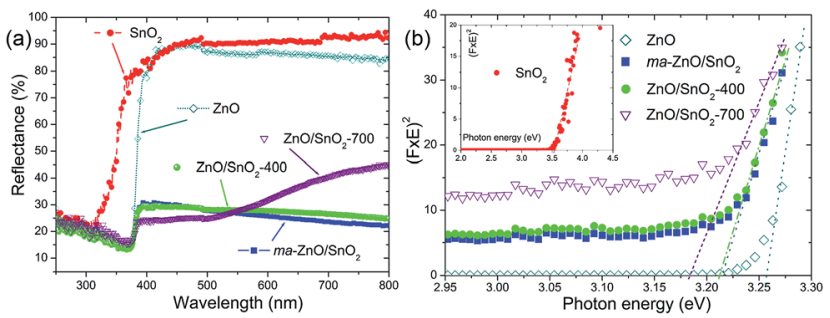

Fig. 8 (a) The UV-Vis diffuse reflectance spectra of pristine metal oxides and photocatalysts, and (b) Kubelka-Munk curves for determination of the band gap energies. The band gaps are attained by the extrapolation procedure. 

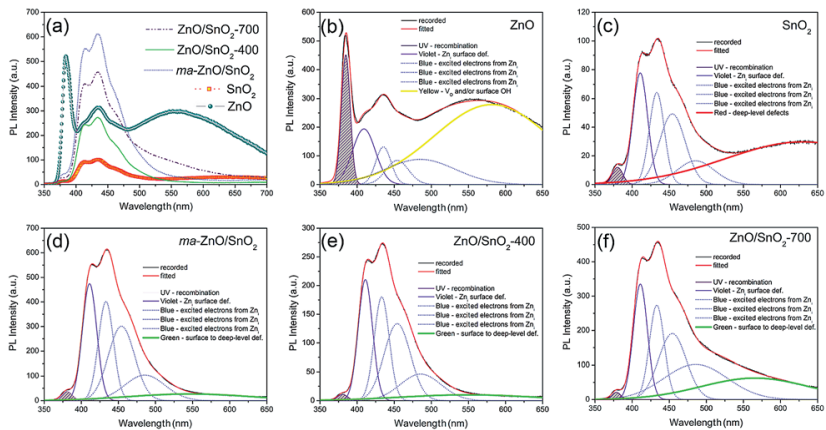

Fig. 9 (a) Photoluminescence spectra of pristine metal oxides and photocatalysts under excitation at $325 \mathrm{~nm}$, (b-f) PL spectra deconvoluted with a Gaussian function.

achieved during mechanical activation. Further annealing at $400{ }^{\circ} \mathrm{C}$ did not influences crystal structure nor phase composition, thus neither influence the band gap energy. However, annealing at $700{ }^{\circ} \mathrm{C}$ red-shifted band gap energy for $0.08 \mathrm{eV}$ as compared to $\mathrm{ZnO}$; it is probably due to both, existence of the surface defects and diffusion of tin cations into $\mathrm{ZnO}$ lattice, which also promote formation of $V_{\mathrm{O}}$.

Photoluminescence study was used to determine type of defects in pristine metal oxides and $\mathrm{ZnO} / \mathrm{SnO}_{2}$ composites. It is known that $\mathrm{ZnO}$ and $\mathrm{SnO}_{2}$ particles have rich defect chemistry $^{41,42}$ and variety of defects may exist in these crystals, in particular, cation vacancy, oxygen vacancy, cation interstitial, oxygen interstitial, as well as antisites. As have been shown, the presence of different defects can result in both, improvement and deterioration of the photocatalytic activity, depending on the type and location of the defects. It is generally accepted that surface defects are favourable, whereas bulk ones only can worsen the photocatalytic activity of $\mathrm{ZnO}$. Thus, determination of defects in photocatalysts can be useful for understanding and further improving of their photoactivity.

The room temperature PL spectra of the photocatalysts are presented in Fig. 9(a). It can be seen that all of the PL spectra show UV emission band, near the band-edge, and a broad visible emission band; however, the spectra vary with milling and annealing. To reveal positions and area (\%) of the hidden emission bands, PL spectra were deconvoluted with multiple Gaussian functions; the data obtained by deconvolution are listed in Table 3, while deconvoluted spectra are presented in Fig. 9(b-f). The PL spectrum of pristine $\mathrm{ZnO}$ is found to be convolution of six Gaussian components centered at 385, 409, 435, 454, 485 and $582 \mathrm{~nm}$, Fig. 9(b). The sharp and intense band at $385 \mathrm{~nm}$ is typical for the near band edge emission and is due to the recombination of the self-excitons of $\mathrm{ZnO}$. The violet emission at $409 \mathrm{~nm}$ can be attributed to the surface zinc vacancies $\left(V_{\mathrm{Zn}}\right) .^{15}$ The blue emission bands at 435,454 and $485 \mathrm{~nm}$ are caused by the transitions of excited electrons from the $\mathrm{Zn}_{\mathrm{i}}$ level to the valence band. ${ }^{15}$ The yellow emission near $580 \mathrm{~nm}$ is due to the doubly charged oxygen vacancy states $\left(V_{\mathrm{O}}^{++}\right)$, representing deep-level i.e. lattice defect. These results are in agreement with Raman spectroscopy ones (Fig. 3) which revealed the existence of oxygen vacancies and zinc interstitials. However, beside of the commonly assumed deep-level defects, the yellow emission can be also attributed to the $\mathrm{Zn}(\mathrm{OH})_{2}$ or OH groups at the $\mathrm{ZnO}$ particles surface. ${ }^{43}$ For the pristine $\mathrm{ZnO}$ powder, used in this study, the existence of surface $\mathrm{OH}$ ions is previously confirmed by XPS analysis. ${ }^{44}$

Deconvoluted PL spectrum of pristine $\mathrm{SnO}_{2}$ powder shows a weak band centered at $380 \mathrm{~nm}$, the violet emission at $410 \mathrm{~nm}$, three blue emission bands peaking at 433, 454 and $486 \mathrm{~nm}$, and a strong broad red emission band at $630 \mathrm{~nm}$, Fig. 9(c). The red emission band is related to deep-level defects within the gap of $\mathrm{SnO}_{2}$, associated with oxygen vacancies and $\mathrm{Sn}$ interstitial formed during synthesis procedure. ${ }^{42}$ The intensities of PL bands in spectrum of $\mathrm{SnO}_{2}$ are significantly smaller as compared to those in PL spectrum of ZnO. PL spectrum of ma$\mathrm{ZnO} / \mathrm{SnO}_{2}$ composite, Fig. 9(d), is consisted of six bands centered at 380, 411, 433, 454, 486 and $546 \mathrm{~nm}$. Comparing to PL spectra of metal oxides, composite one did not shows yellow or red emissions attributed to deep-level defects, instead, green emission appears at $546 \mathrm{~nm}$. Green emission implicates to surface defects, as well as the defects just below the crystallite surface. ${ }^{43}$ These results confirmed that milling considerably influenced the relative concentration ratio of surface defects to bulk defects. PL spectra of annealed composites show almost the same emission bands as that of ma- $\mathrm{ZnO} / \mathrm{SnO}_{2}$. However, results of the deconvolution point to different band area ratio of

Table 3 Position and area of emission bands in PL spectra obtained after deconvolution by a Gaussian function

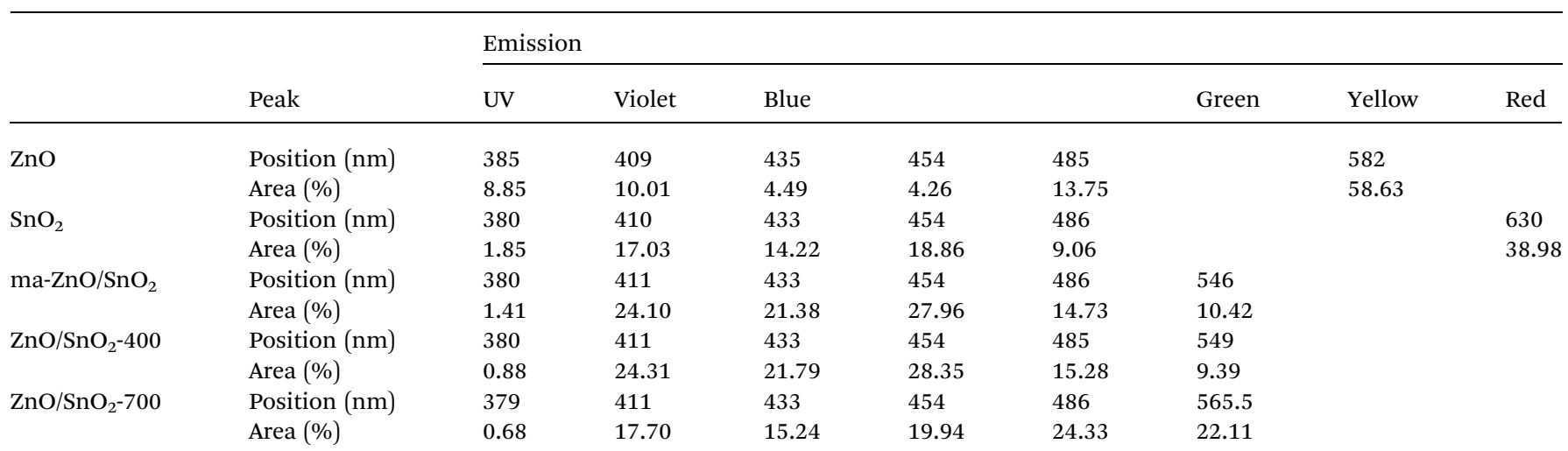



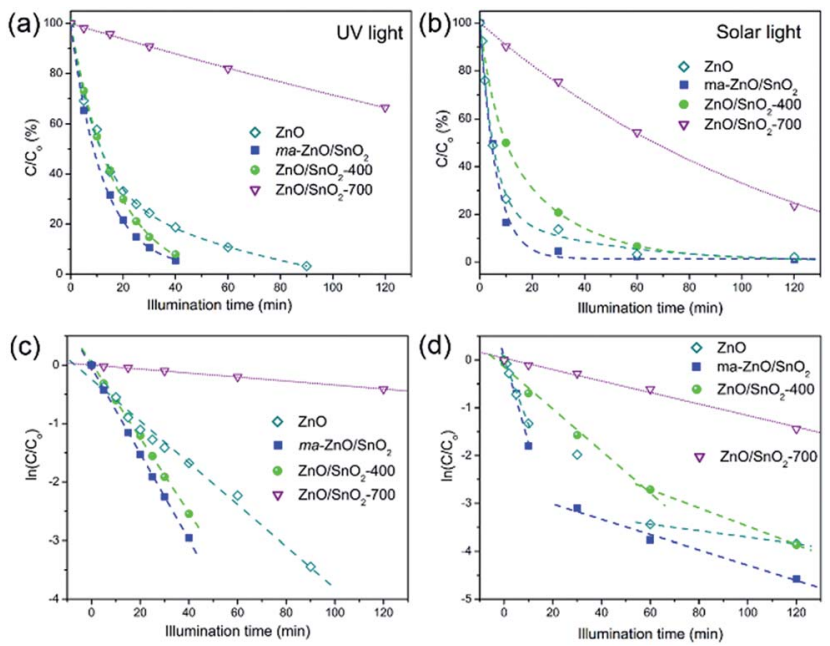

Fig. 10 Photocatalytic efficiency, and appropriate first-order reaction kinetic plots, for de-colorization of $[\mathrm{MB}]_{i}=10 \mathrm{ppm}$ in the presence of examined samples, under: ( $a, c)$ UV, and (b, d) natural sunlight illumination.

bulk defects to surface defect, which is somewhat higher for $\mathrm{ZnO} / \mathrm{SnO}_{2}-700$. Slightly larger amount of the bulk defects in $\mathrm{ZnO} / \mathrm{SnO}_{2}-700$ is due to the formation of $\mathrm{Zn}_{2} \mathrm{SnO}_{4}$ accompanied by $V_{\mathrm{O}}$, which is also in accordance with results of the Raman spectroscopy. Results of the PL spectroscopy clearly reveal that the relative concentration of surface defects is larger in the composites as compared to pristine $\mathrm{ZnO}$ while the number of exciton recombination is reduced.

Fig. 10(a and b) shows the efficiency of the photocatalytic decolorization of $\mathrm{MB}$ dye in the presence of pristine $\mathrm{ZnO}$ and prepared composites under two different illumination sources. It was found that less than $1 \%$ of the MB was adsorbed on the photocatalysts after the equilibration of the dye-photocatalyst suspension in a dark. The neglected adsorption is due to a relatively small specific surface area. When UV light was used as illumination source composites ma- $\mathrm{ZnO} / \mathrm{SnO}_{2}$ and $\mathrm{ZnO} /$ $\mathrm{SnO}_{2}-400$ show improved activity compared to pristine $\mathrm{ZnO}$, while the lowest efficiency was observed when $\mathrm{ZnO} / \mathrm{SnO}_{2}-700$ was applied, Fig. 10(a). The linear kinetic curves of the $\ln \left(C / C_{\mathrm{o}}\right)$ versus the illumination time plot, Fig. 10(c), implicate first order reaction kinetics. The calculated kinetic parameters, the rate constant of photo-de-colorization $\left(K_{1}\left[\mathrm{~min}^{-1}\right]\right)$ and $t_{1 / 2}[\mathrm{~min}]$, are denoted in Table 4 . When the most efficient photocatalysts, ma$\mathrm{ZnO} / \mathrm{SnO}_{2}$ and $\mathrm{ZnO} / \mathrm{SnO}_{2}-400$, were used $\mathrm{MB}$ dye solution was

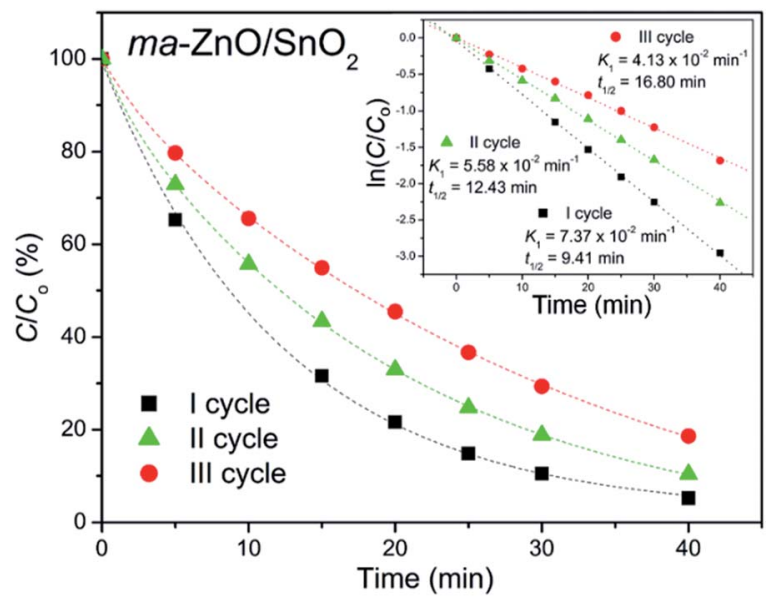

Fig. 11 Recycling test of $\mathrm{ma}-\mathrm{ZnO} / \mathrm{SnO}_{2}$ photocatalyst on de-colorization of $[\mathrm{MB}]_{\mathrm{i}}=10 \mathrm{ppm}$ under UV light illumination.

completely de-colorized after $40 \mathrm{~min}$, whereas the time necessary for the de-colorization of $50 \%$ of the dye was $t_{1 / 2}=9.42$ and $10.86 \mathrm{~min}$, respectively. When the pristine $\mathrm{ZnO}$ was used, $\mathrm{MB}$ dye was completely de-colorized after $90 \mathrm{~min}$, while $t_{1 / 2}=$ $19.47 \mathrm{~min}$.

When natural sunlight was used as the illumination source, the activity decreases in order ma- $\mathrm{ZnO} / \mathrm{SnO}_{2}<\mathrm{ZnO}<\mathrm{ZnO} / \mathrm{SnO}_{2}$ $400<\mathrm{ZnO} / \mathrm{SnO}_{2}-700$, Fig. 10(b). Fig. 10(d) shows kinetic plots for sunlight driven photocatalytic de-colorization of $\mathrm{MB}$ in the presence of examined samples. Each of the curves can be separated into two linear segments with different slopes. For each slope the rate constant of photo-de-colorization was calculated and denoted as $K_{1}^{(1)}$ and $K_{1}^{(2)}$, also, $t_{1 / 2}^{(1)}$ and $t_{1 / 2}^{(2)}$ were calculated and listed in Table 4 . When ma- $\mathrm{ZnO} / \mathrm{SnO}_{2}$ was used MB was almost completely (97\%) de-colorized after $30 \mathrm{~min}$ and $t_{1 / 2}^{(1)}$ was equal to $3.85 \mathrm{~min}$. That is significantly faster than $60 \mathrm{~min}$, which is time necessary to decolorize $97 \%$ of $\mathrm{MB}$ in the presence of $\mathrm{ZnO}$, with $t_{1 / 2}^{(1)}$ of $5.10 \mathrm{~min}$.

In order to test photocatalytic stability of $\mathrm{ma}-\mathrm{ZnO} / \mathrm{SnO}_{2}$ under long run working conditions, the degradation of MB was determined in repeated cycles without the photocatalyst being subject to any cleaning treatments after degradation process was completed. The photocatalytic activity of composite was compared in three consecutive runs and obtained data are presented in Fig. 11. It should be stressed that the activity of ma$\mathrm{ZnO} / \mathrm{SnO}_{2}$ is preserved under long run working conditions. Moreover, after the ma- $\mathrm{ZnO} / \mathrm{SnO}_{2}$ photocatalysts had been

Table 4 Kinetic parameters for photocatalytic de-colorization of $[\mathrm{MB}]=10 \mathrm{ppm}$; [photocatalyst] $=100 \mathrm{mg} / 100 \mathrm{ml}$, $\mathrm{pH}$ of the solution $=$ natural (5.5)

\begin{tabular}{|c|c|c|c|c|c|c|}
\hline Sample & \multicolumn{2}{|l|}{ UV lamp } & \multicolumn{4}{|c|}{ Natural sunlight } \\
\hline $\mathrm{ma}-\mathrm{ZnO} / \mathrm{SnO}_{2}$ & $7.36 \times 10^{-2}$ & 9.42 & $1.80 \times 10^{-1}$ & 3.85 & $1.59 \times 10^{-2}$ & 43.59 \\
\hline $\mathrm{ZnO} / \mathrm{SnO}_{2}-400$ & $6.38 \times 10^{-2}$ & 10.86 & $4.40 \times 10^{-2}$ & 15.75 & $1.91 \times 10^{-2}$ & 36.29 \\
\hline $\mathrm{ZnO} / \mathrm{SnO}_{2}-700$ & $3.42 \times 10^{-3}$ & 202.67 & $1.20 \times 10^{-2}$ & 57.76 & - & - \\
\hline
\end{tabular}


loaded with MB and UV light illuminated, and then consecutively recovered, the crystal structure of the photocatalyst was checked by XRD. The recovered photocatalyst showed almost the same XRD pattern as the initial one (see Fig. 2), which indicates that ma- $\mathrm{ZnO} / \mathrm{SnO}_{2}$ has a stable crystal structure during long-term photocatalysis and is suitable for recycling and reuse with a slight loss of the photocatalytic activity.

The most efficient photocatalyst, ma- $\mathrm{ZnO} / \mathrm{SnO}_{2}$, was also tested for the degradation of phenol, as a representative of pollutants that have no absorption in the visible range. Fig. 12 shows the efficiency of the photocatalytic degradation of phenol in the presence of ma- $\mathrm{ZnO} / \mathrm{SnO}_{2}$ photocatalysts under natural sunlight illumination. We found that less than $2 \%$ of the phenol concentration was adsorbed on the ma- $\mathrm{ZnO} / \mathrm{SnO}_{2}$ during $1 \mathrm{~h}$ of the equilibration of the phenol-photocatalyst suspension in a dark. Under direct sunlight illumination the phenol concentration rapidly decreased; after $30 \mathrm{~min}$, more than $60 \%$ of phenol was removed, while after $2 \mathrm{~h}$ phenol was completely removed from the system. Accordingly, ma- $\mathrm{ZnO} / \mathrm{SnO}_{2}$ can be used as an effective photosensitizer for phenol, as well as for the MB dye. Besides, it was found that the decrease of the total organic carbon (TOC) via mineralization was much slower than the degradation of phenol, Fig. 12. This discrepancy was previously explained as a result of the phenol photo-oxidation to benzoquinone and its further slow degradation to $\mathrm{CO}_{2}$ and $\mathrm{H}_{2} \mathrm{O}^{45}$

Presented results promote $\mathrm{ma}-\mathrm{ZnO} / \mathrm{SnO}_{2}$ as efficient photocatalysts under both, UV and natural sunlight. PL results implicate that the enhanced photo-activity of $\mathrm{ma}-\mathrm{ZnO} / \mathrm{SnO}_{2}$ as compared to pristine $\mathrm{ZnO}$ is due to the surface defects. In the case of UV-light driven photoreaction, the surface defects increased the separation of photogenerated carriers, thereby hindering recombination. What's more significant, the surface defects contributes to the visible light absorption. The presence of $\mathrm{Zn}_{\mathrm{i}}$ point defects contributes to the visible light absorption due to the defect level located in the band gap, at $0.22 \mathrm{eV}$ below the conductive band ${ }^{46}$ (narrowing band gap to about $3.15 \mathrm{eV}$ or

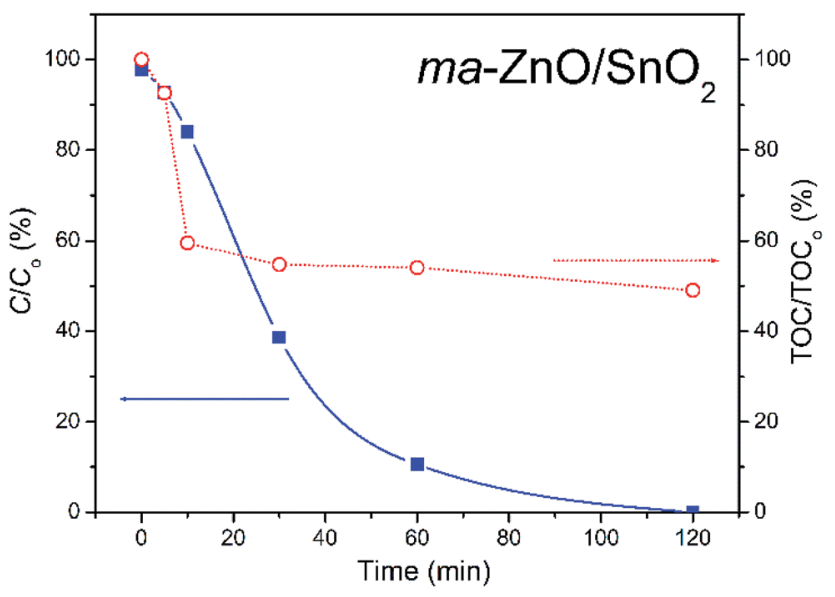

Fig. 12 Photocatalytic efficiency for the degradation of [phenol $]_{i}=$ $10 \mathrm{ppm}$ in the presence of $\mathrm{ma}-\mathrm{ZnO} / \mathrm{SnO}_{2}$, under natural sunlight illumination with TOC efficiency. (a)

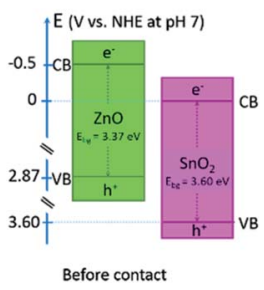

(b)

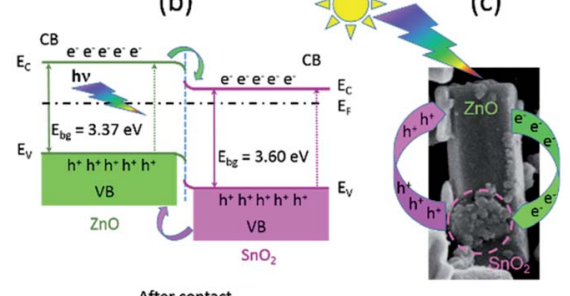

After contact

Fig. 13 Band structures for: (a) $\mathrm{ZnO}$ and $\mathrm{SnO}_{2}$ before contact, (b) $\mathrm{ZnO}$ / $\mathrm{SnO}_{2}$ after contact, and (c) illustrative representation of the mechanism of photoexcited charge-carrier transport in the $\mathrm{ZnO} / \mathrm{SnO}_{2}$ hetero-particle.

$400 \mathrm{~nm})$. This defects also promotes charge transfer and suppress electron-hole recombination.

Besides intrinsic defects, the $\mathrm{ZnO} / \mathrm{SnO}_{2}$ heterojunction particles are involved in enhanced photocatalytic activity. A prominent role of $\mathrm{ZnO} / \mathrm{SnO}_{2}$ heterojunction particles in the separation of photogenerated electrons and holes, which further improved photocatalytic activity, had been previously explained as a result of band energy alignment. ${ }^{47}$ Actually, both $\mathrm{ZnO}$ and $\mathrm{SnO}_{2}$ belong to n-type semiconductors; among them, $\mathrm{SnO}_{2}$ is a better electron acceptor than $\mathrm{ZnO}$ because the conduction band potential of $\mathrm{SnO}_{2}(0 \mathrm{~V} v s$. normal hydrogen electrode (NHE) at $\mathrm{pH} 7$ ) is more positive than that of $\mathrm{ZnO}$ $(-0.5 \mathrm{~V} v s$. NHE at $\mathrm{pH} 7)$, Fig. 13(a). ${ }^{3,48}$ It may be expected that a type-II heterostructure ${ }^{49}$ with a staggered alignment at the heterojunction is formed for $\mathrm{ma}-\mathrm{ZnO} / \mathrm{SnO}_{2}$ heterojunction particles, Fig. 13(b). ${ }^{47}$ In such a case, the electron-hole pairs generated under sunlight illumination will be separated due to thermodynamic favouring: electrons will move from the $\mathrm{CB}$ energy level of $\mathrm{ZnO}$ to the $\mathrm{SnO}_{2}$ one and holes will move from the $\mathrm{VB}$ level of $\mathrm{SnO}_{2}$ to the $\mathrm{ZnO}$ one. This process promotes the formation of a charge transfer state and the spatial separation of the photogenerated carriers within the $\mathrm{ZnO} / \mathrm{SnO}_{2}$ heterojunction particles. ${ }^{47}$

The substitution of $\mathrm{Zn}^{2+}$ ions for $\mathrm{Sn}^{4+}$ results in surface modification and formation of more $V_{\mathrm{O}}$ in order to compensate the positive charge. The surface $V_{\mathrm{O}}$ act as charge carriers of holes, thus, facilitated charge separation. However, annealing at $700{ }^{\circ} \mathrm{C}$ for $2 \mathrm{~h}$ deteriorate the photocatalytic activity of the composite. The activity decreased due to the formation of both, photoinactive $\mathrm{Zn}_{2} \mathrm{SnO}_{4}$ and the bulk oxygen vacancies (with the energy level close to the middle of the gap) ${ }^{50}$ acting as a charge recombination centers.

\section{Conclusions}

$\mathrm{ZnO} / \mathrm{SnO}_{2}$ composite was processed by mechanical milling of $\mathrm{ZnO}$ and $\mathrm{SnO}_{2}$ commercial powders. In this process, $\mathrm{SnO}_{2}$ particles were significantly reduced and decorated on the surface of larger hexagonal $\mathrm{ZnO}$ submicro-rods. The photocatalytic activity study showed that $\mathrm{ZnO} / \mathrm{SnO}_{2}$ composite particles possess an enhanced efficiency for $\mathrm{MB}$ de-colorization as compared to pristine $\mathrm{ZnO}$, under both UV and sunlight. The 
results of structural, morphological, textural and optical properties of $\mathrm{ZnO} / \mathrm{SnO}_{2}$ composite and ingredients implicate to a significant contribution of surface defects in enhancement of the photoactivity. A high relative concentration ratio of surface defects to bulk defects was introduced by milling, also, by existence of $\mathrm{ZnO} / \mathrm{SnO}_{2}$ heterojunction particles. Surface defects narrowed band gap of $\mathrm{ZnO} / \mathrm{SnO}_{2}$ composite, thus increasing the capacity of visible light absorption as compared to ZnO. Surface defects, in particular zinc interstitials and oxygen vacancies, facilitated charge separation, thereby hindering the recombination of photogenerated carriers as compared to pristine $\mathrm{ZnO}$. Annealing of composite at $700{ }^{\circ} \mathrm{C}$ stimulate diffusion of tin(Iv) cations into the $\mathrm{ZnO}$ particles and formation of both, photoinactive $\mathrm{Zn}_{2} \mathrm{SnO}_{4}$ and the bulk oxygen vacancies which acts as recombination centers for carriers, resulting in the loss of photoactivity.

This study aims to draw attention to the mechanical activation as an inexpensive and environmental friendly technique for the large-scale production of the long-run working composite with an enhanced photocatalytic activity under illumination of either UV or sunlight.

\section{Conflicts of interest}

There are no conflicts to declare.

\section{Acknowledgements}

This study was supported by the Ministry of Education, Science and Technological Development of the Republic of Serbia under grant no III45004. The authors are grateful to Dr N. Abazovic from the Vinča Institute of Nuclear Sciences, for UV-vis DRS results, Dr B. Hadžić from Institute of Physics, for Raman measurements and Prof. Dr S. Stojadinović from Faculty of Physics, for PL measurements. The authors appreciate the help of Prof. Dr Ilija Brčeski and experts in charge for TOC measurements in the MOL Institute from Stara Pazova.

\section{References}

1 A. Fujishima and K. Honda, Nature, 1972, 238(5358), 37-38. 2 A. Hamrouni, N. Moussa, F. Parrino, A. Di Paola, A. Houas and L. Palmisano, J. Mol. Catal. A: Chem., 2014, 390, 133-141.

3 Q. Luo, L. Wang, D. Wang, R. Yin, X. Li, J. An and X. Yang, J. Environ. Chem. Eng., 2015, 3, 622-629.

4 A. Hamrouni, H. Lachheb and A. Houas, Mater. Sci. Eng., B, 2013, 178, 1371-1379.

5 S. K. Pardeshi and A. B. Patil, Sol. Energy, 2008, 82, 700-705. 6 E. Yassitepe, H. C. Yatmaz, C. Öztürk, K. Öztürk and C. Duran, J. Photochem. Photobiol., A, 2008, 198, 1-6.

7 R. Wu, Y. Yang, S. Cong, Z. Wu, C. Xie, H. Usui, K. Kawaguchi and N. Koshizaki, Chem. Phys. Lett., 2005, 406, 457-461.

8 J. A. Duffie and W. A. Beckman, Solar engineering of thermal processes, John Wiley \& Sons, Inc., Hoboken, New Jersey, 4th edn, 2013.

9 S. Liu, C. Li, J. Yu and Q. Xiang, CrystEngComm, 2011, 13, 2533-2541.
10 S. Baruah, R. F. Rafique and J. Dutta, Nano, 2008, 3, 399-407.

11 S. Baruah, S. K. Pal and J. Dutta, Nanosci. Nanotechnol.-Asia, 2012, 2, 90-102.

12 X. Chen, L. Liu, P. Y. Yu and S. S. Mao, Science, 2011, 331, 746-750.

13 W. Li, R. Liang, A. Hu, Z. Huanga and Y. N. Zhou, RSC Adv., 2014, 4, 36959-36966.

14 T. Xia, P. Wallenmeyer, A. Anderson, J. Murowchick, L. Liu and X. Chen, RSC Adv., 2014, 4, 41654-41658.

15 D. Chen, Z. Wang, T. Ren, H. Ding, W. Yao, R. Zong and Y. Zhu, J. Phys. Chem. C, 2014, 118, 15300-15307.

16 T. Jia, J. Zhao, F. Fu, Z. Deng, W. Wang, Z. Fu and F. Meng, Int. J. Photoenergy, 2014, 197824.

17 R. Lamba, A. Umar, S. K. Mehta and S. K. Kansal, Talanta, 2015, 131, 490-498.

18 Q. Wang, D. Jiao, J. Lian, Q. Ma, J. Yu, H. Huang, J. Zhong and J. Li, J. Alloys Compd., 2015, 649, 474-482.

19 C. C. Li, X. M. Yin, Q. H. Li and T. H. Wang, CrystEngComm, 2011, 13, 1557-1563.

20 M. M. Rashad, A. A. Ismail, I. Osama, I. A. Ibrahim and A.-H. T. Kandil, Clean: Soil, Air, Water, 2014, 42, 657-663.

21 Y. Zhou, C. Xia, X. Hu, W. Huang, A. A. Aref, B. Wang, Z. Liu, Y. Sun, W. Zhou and Y. Tang, Appl. Surf. Sci., 2014, 292, 111116.

22 Z. Wen, G. Wang, W. Lu, Q. Wang, Q. Zhang and J. Li, Cryst. Growth Des., 2007, 7, 1722-1725.

23 T. Jia, W. Wang, F. Long, Z. Fu, H. Wang and Q. Zhang, J. Phys. Chem. C, 2009, 113, 9071-9077.

24 A. Dodd, A. McKinley, M. Saunders and T. Tsuzuki, Nanotechnology, 2006, 17, 692-698.

25 A. A. Coelho, Topas-Academic, 2004.

26 H. P. Klug and L. E. Alexander, X-ray diffraction procedures for polycrystalline and amorphous materials, Wiley, New York, 4th edn, 1954.

27 S. K. Pardeshi and A. B. Patil, J. Mol. Catal. A: Chem., 2009, 308, 32-40.

28 F. Rouquerol, J. Rouquerol and K. Sing, Adsorption by powders and porous solids, Academic Press, London, 1999.

29 E. P. Barrett, L. G. Joyner and P. P. Halenda, J. Am. Chem. Soc., 1951, 73, 373-380.

30 W. Cun, Z. Jincai, W. Xinming, M. Bixian, S. Guoying, P. Ping'an and F. Jiamo, Appl. Catal., B, 2002, 39, 269-279.

31 L. Ren, D. Chen, Z. Hu, Z. Gao, Z. Luo, Z. Chen, Y. Jiang, B. Zhao, C. M. Lawrence $\mathrm{Wu}$ and C.-H. Shek, RSC Adv., 2016, 6, 82096-82102.

32 R. D. Shannon and C. T. Prewitt, Acta Crystallogr., Sect. B: Struct. Crystallogr. Cryst. Chem., 1969, 25, 925-946.

33 L. Li, J. Liu, Y. Su, G. Li, X. Chen, X. Qiu and T. Yan, Nanotechnology, 2009, 20, 155706.

34 L. Zheng, C. Chen, Y. Zheng, Y. Zhan, Y. Cao, X. Lin, Q. Zheng, K. Wei and J. Zhu, Appl. Catal., B, 2014, 148-149, 44-50.

35 A. Sadollahkhani, I. Kazeminezhad, J. Lu, O. Nur, L. Hultman and M. Willander, RSC Adv., 2014, 4, 3694036950.

36 Y.-d. Wang, C.-l. Ma, X.-d. Sun and H.-d. Li, Nanotechnology, 2002, 13, 565-569. 
37 R. Cuscó, E. Alarcón-Lladó, J. Ibáñez, L. Artús, J. Jiménez, B. Wang and M. J. Callahan, Phys. Rev. B: Condens. Matter, 2007, 75, 165202.

38 S. Marković, V. Rajić, A. Stanković, L. Veselinović, J. Belošević-Čavor, K. Batalović, N. Abazović, S. D. Škapin and D. Uskoković, Sol. Energy, 2016, 127, 124-135.

39 A. Londono-Calderon, F. F. Jurado-Lasso, J. D. RomeroSalazar, N. Jurado-Lasso and J. F. Jurado, J. Nanomater., 2014, 340384.

40 A. Stanković, Z. Stojanović, L. Veselinović, S. D. Škapin, I. Bračko, S. Marković and D. Uskoković, Mater. Sci. Eng., B, 2012, 177, 1038-1045.

41 A. Janotti and C. G. Van de Walle, Phys. Rev. B: Condens. Matter Mater. Phys., 2007, 76, 165202.

42 I. I. Gontia, M. Baibarac and I. Baltog, Phys. Status Solidi B, 2011, 248, 1494-1498.

43 A. B. Djurišić, Y. H. Leung, K. H. Tam, Y. F. Hsu, L. Ding, W. K. Ge, Y. C. Zhong, K. S. Wong, W. K. Chan, H. L. Tam,
K. W. Cheah, W. M. Kwok and D. L. Phillips, Nanotechnology, 2007, 18, 095702.

44 A. Peleš, V. P. Pavlović, S. Filipović, N. Obradović, L. Mančić, J. Krstić, M. Mitrić, B. Vlahović, G. Rašić, D. Kosanović and V. B. Pavlović, J. Alloys Compd., 2015, 648, 971-979.

45 R. Qiu, D. Zhang, Y. Mo, L. Song, E. Brewer, X. Huang and Y. Xiong, J. Hazard. Mater., 2008, 156, 80-85.

46 H. Zeng, G. Duan, Y. Li, S. Yang, X. Xu and W. Cai, Adv. Funct. Mater., 2010, 20, 561-572.

47 W. Tian, T. Zhai, C. Zhang, S.-L. Li, X. Wang, F. Liu, D. Liu, X. Cai, K. Tsukagoshi, D. Golberg and Y. Bando, Adv. Mater., 2013, 25, 4625-4630.

48 S. Girish Kumar and K. S. R. Koteswara Rao, RSC Adv., 2015, 5, 3306-3351.

49 M. R. Gholipour, C.-T. Dinh, F. Béland and T.-O. Do, Nanoscale, 2015, 7, 8187-8208.

50 C. H. Ahn, Y. Y. Kim, D. C. Kim, S. Kumar Mohanta and H. K. Cho, J. Appl. Phys., 2009, 105, 013502. 